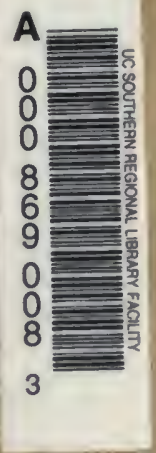

ELDERTON

The Relative Strength of Nurture and Nature

HQ

751

E4 
Digitis oy the tho... is chive in with funding tom Microsoft Corpowion

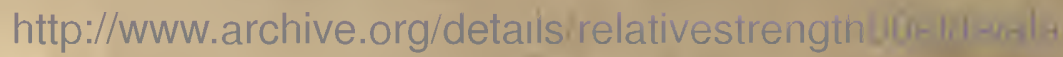




\section{The Relative Strength of Nurture and Nature,}

(SECOND, MUCH ENLARGED EDITION)

\section{PART I \\ THE RELATIVE STRENGTH OF NURTURE} AND NATURE

(Second Edition, Revised)

BY

ETHEL M. ELDERTON,

GALTON RESEARCH FELLOW

PART II

SOME RECENT MISINTERPRETATIONS OF THE PROBLEM OF NURTURE AND NATURE

(First Issue)

BY

KARL PEARSON, F.R.S., GALTON PROFESSOR

CAMBRIDGE UNIVERSITY PRESS

C. F. Clay, Manager

LONDON: FETTER LANE, E.C.

EDINBURGH : IOO, PRINCES STREET

ALSO

H. K. LEWIS AND CO., LTD., I36, GOWER STREET, LONDON, W.C.

WILLIAM WESLEY AND SON, 28, ESSEX STREET, LONDON, W.C.

CHICAGO: UNIVERSITY OF CHICAGO PRESS

BOMBAY, CALCUTTA AND MADRAS: MACMILIAN AND CO., LIMITED

TORONTO: J. M. DENT AND SONS, LIMITED

TOKYO: THE MARUZEN-KABUSHIKI-KAISHA

I9I5

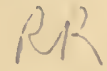




\section{PREFATORY NOTE}

The statistical material used in these two lectures is partly drawn from Dr David Heron's memoir The Infuence of Unfavourable Home Environment and Defective Physique on the Intelligence of School Children (Galton Laboratory Memoirs, No. VIII) and from $A$ First Study of the Inheritance of Vision and of the Relative Influence of Heredity and Environment on Sight by Amy Barrington and Karl Pearson (Galton Laboratory Memoirs, No. V), but is also largely based on hitherto unpublished material, which cannot be issued in bulk until the laboratory staff has greater leisure and more ample funds for publication than are at present available.

CAMBRIDGE: PRINTED BY JOHN CLAY, M.A. AT THE UNIVERSITY PRESS 


\section{PART $I^{1}$}

\section{THE RELATIVE STRENGTH OF NURTURE AND NATURE}

When we approach the fundamental problems of human life, and endeavour to study the causes which make for the physical and mental fitness of a nation, we are at once struck by the vast network of associated factors, which render so complex any attempt at a solution of the simplest problem in the relationship of nurture and environment to human progress.

We might for example discover that the mentally and physically fitter child comes from the cleaner and less crowded home, and therefore argue that the spread of such homes is a condition for national progress. But further investigation may show that the essential condition for such homes is the existence of mentally and physically fit parents, and that the fitness of the children flows after all from the parentage and not from the home.

Or again if we take the problem of employment of mothers, we might discover that employed mothers have the healthier children, and we might on this ground oppose any attempt to restrict the factory work of women during childbearing years. But on further investigation we might ascertain that such mothers are, on the average older and have older children, from whom time has weeded the weaklings, and that the problem cannot be solved by the simple question of the physique of the children of employed and unemployed mothers, without regard to the age distribution of the children.

Once more it is conceivable that we might find the deathrate of innkeepers much in excess of the deathrate of the clergy, and

1 This paper was originally delivered as the seventh of a course of Eight Lectures on National Eugenics at the Galton Laboratory, I909. 
overlook the fact that the average age at starting the occupation of innkeeper is far higher than that of entering the church, because ultimately to keep an inn is the ambition of men, who begin life in a variety of other callings. As a last illustration we may take the problem of the effect of the drinking of the father on the health and ability of the offspring. We might find that the father who drinks had abler and physically better developed sons than the non-drinker. Yet on closer investigation it might appear (i) that on the average the drinker was the abler workman, and thus the apparently greater ability of the offspring was really an hereditary matter, (ii) that the abler workman got higher wages, and thus, notwithstanding the drink, the food at home, especially perhaps in the earlier days of the family life, had been ampler and of better quality. There is hardly a single problem of parental occupation and habit, of home environment and school influence which is not of the greatest complexity, and full of pitfalls for even the most cautious statistician. And if this be true, what must be said for the philanthropist and social reformer who without hesitation preach that social salvation lies in this or that line of conduct? What must be our judgment of the "practical man" and the statesman who legislate in the direction indicated by the falling scale of popular opinion, without any real examination of the intense complexity, the subtle biological effects of even slight changes in the factors on which our national weal depends?

A factory act may be carried owing to a wave of popular emotion, which paints the horrors of child-labour in the mills. Twenty years afterwards it may become apparent that children were taken care of because their labour was of value, but that their value depending on their labour, they are, since the act, an unmarketable commodity and have ceased to be born on this very account ${ }^{1}$.

What guide can we take to indicate the path of true social reform through such a tangle of cause and effect as we find involving the relative influence of nature and nurture on human life? It is not enough to show that results are associated with this or that factor; we have a vast complex of associated factors, and out of this complex we have in some way to pick out the more important and in a certain sense the fundamental factors. The only effective method by which it seems possible at present to approach such a problem is that of

1 For a fuller discussion of this point see Pearson: The Problem of Prachcal Eugenics, Galton Laboratory Lecture Series V; and Elderton: The English Birthrate, Part I, North of the Humber, Galton Laboratory Memoirs, Nos. XIX and XX. 
correlation $^{1}$. Taking the social conditions we wish to modify, we must study their correlation with as many factors as we can possibly measure. In the choice of these factors we must of course be guided by the reasonable probability of association and by the limits of human life and energy. The correlations of a multiplicity of factors being known we may justifiably assume that the factors with the highest correlations are, among those dealt with by us, the most important, and then the process of "partial correlation" will guide us still further towards a final judgment of what fundamentally are social cause and effect.

We admit to the full that even then we may not have avoided all danger of pitfalls, that we may have overlooked possible factors, and that spurious correlation may have arisen from all sorts of disregarded selective processes. The prudent statistician will always advance his conclusions with a word of caution; he will simply state that they are those which reasonably follow from the data provided. But at the same time he will not hesitate to proclaim that in the present state of our knowledge the calculus of correlation is the sole rational and effective method available for attacking these urgent social problems. If that calculus throws no light, when properly applied, on social dynamics, then the only solution is to develop a finer statistical calculus; no other instrument, least of all general reasoning with appeal to social or moral prejudgments, can at present aid us in our difficulties with regard to what makes for, and what mars national fitness. Indeed we venture to go further and to assert that much of the canon of social conduct and moral action as it has existed in the past and as it widely exists at the present will be found inadequate or even antisocial, when we understand more fully the manner in which legislation, social custom, and philanthropy (in the old sense) tend to modify the biological factors on which human progress so largely depends.

There is no one with the least biological knowledge who would

1 The coefficient of correlation measures the amount of resemblance or association between characteristics of individuals or of things; it is represented by a decimal which lies between o and I. As the correlation coefficient rises to I we approach a condition of absolute dependence. As it falls to o we approach a condition of absolute independence. Thus the correlation between right and left femur in man is .96 which is practically unity, i.e. almost perfect dependence as we should expect. The inheritance between stature of father and son is $5 \mathrm{I}$, half-way between absolute dependence and absolute independence. 
refuse to admit the enormous part played by environment in modifying living forms. This modification, however, is of two kinds:

(a) A change in the somatic characters of the individual following upon his transfer to different surroundings or his treatment to different conditions of nurture; this environmental change in the individual appears to be more marked in plants than in animals. If it is in any case persistent after the offspring of the individual have returned to the original environment, most biologists would assert that a germinal change of some kind, an unrecognized selection of germ plasm, has taken place in the original individual.

(b) A change in the germ characters of the race, owing to the environment selecting for survival a certain differential class of individuals, and their somatic characters thus becoming more frequent and possibly dominant in the population owing to the strength of heredity.

Now we are not in any way concerned with a consideration of this second modification due to environment. We have solely to deal with the problem of the extent to which the offspring are modified by an indirect environmental factor, namely the occupations and habits of their parents and the condition of their homes. We are not considering (b), for we are dealing with surviving children, and not with the selective infantile deathrate. Now the influence of the parental environmental factor on the welfare of children is of fundamental importance, quite apart from the selective infantile deathrate and the possibility of the inheritance of acquired characters. It is at present and has been in the past the chief direction of legislative and philanthropic attack on social evils. Degeneracy of every form has been attributed to poverty, bad housing, unhealthy trades, drinking, industrial occupation of women, and other direct or indirect environmental influences on offspring. If we could by education, by legislation, or by social effort change the environmental conditions, would the race at once rise to a markedly higher standard of physique and mentality? Much, if not the whole of the battle for social reform has been based on the assumption that this question was obviously to be answered in the affirmative. No direct investigation has really ever been made of the intensity of the influence of environment on man. To modify the obviously repellent was the immediate instinct of the more gently nurtured and controlling social class. Was this direction of social reform really capable of effecting any substantial change? Nay by lessening the selective deathrate may it not have contributed 
to emphasizing the very evils it was intended to lessen? These are the problems which occur to the eugenist and call for investigation and if possible settlement.

The outlines of our enquiry are not hard to sum up. We know from a variety of investigations that the correlation between physical and mental characters in parent and offspring is about $\cdot 45$ to $\cdot 50$. The first question to be asked is: Are the physical and mental characters of children correlated with their or their parents' environment to a higher, an equal, or a lesser extent? But even the answer to this first question will not finally solve the relative intensity of the environmental and heredity factors. We have still to ask how far the parents' physical and mental characters are productive of the observed environment. It is conceivable that the relation between children's physique, for example, and parental occupation is an indirect result of the inheritance of physique and a correlation between parents' physique and their occupation. In other words, what we are attributing to environment may be a secondary influence of heredity itself. A weakling may have no option but to follow an unhealthy trade, a man is a tailor or shoemaker, because he has not the physique needful for smith or navvy. His offspring may be physically inferior because he is a weakling and not because he follows an unhealthy trade. Clearly, to solve our problem, we must know if there be any correlation between the same character in the parent as we are observing in the child and the environment we are correlating with the child's character. Unfortunately data enabling us to determine the relationship of any mental or physical character of the parent with the environment which is supposed to influence the child is rarely forthcoming. We have, however, some information which may help us indirectly in our consideration of this part of the enquiry.

After this preliminary warning as to the difficulties of the problem of heredity and environment we propose to consider what evidence is available for determining the relative intensity of nature and nurture in the case of man. The material at our disposal may be summed up as follows:

I. The Report on the Physical Condition of fourteen hundred school children in the City of Edinburgh, with some account of their homes and surroundings, issued by the Charity Organization Society. Information is given as to the number of children, living and dead, the number of rooms, rent, father's work and wages, mother's work, work and wages of other members of the family, and age, height, 
weight, intelligence, condition of teeth, eyes, ears, nose and throat of the school children, and an account of the home in each case; information is given as to the drinking of the parents, cleanliness of the home, morality of the parents, \&ic.

For this splendid piece of research school teachers, doctors, and workers belonging to the C.O.S. have combined; information has been sought from many sources and infinite pains must have been taken. It is a pleasure to work from such a report, but one longs at the same time that the numbers were ten times as great, and that the C.O.S. might obtain a far larger band of workers who would investigate in like manner the condition of fourteen thousand instead of fourteen hundred school children well distributed over the whole of Great Britain. The machinery now exists for the medical examination of school children, but from the point of view of the eugenist it will be of comparatively little value for measuring the effects of environment unless the children are followed into their homes, and information is collected and recorded as has been done by the C.O.S. in Edinburgh.

II. A Record of Measurements \&c. of children attending in 1905 the public schools in Glasgow, lent to us by the Scottish Education Department. We have from this source information about 72,857 school children; among other facts recorded are the age, height and weight of the children and the occupation of the father and employment of the mother.

III. An account of the children in the special schools in Manchester, kindly provided for us by Miss Dendy. Among other information the health and intelligence of the brothers and sisters of the defective children under consideration are given, and the extent of drinking and the health of the parents.

The main points to which we have turned our attention up to the present time are:

(I) The influence of the employment of mothers on the physique of their children.

(2) The influence of the occupation of the father on the physique of the children.

(3) The influence of drink in the parents on the height, weight, general health and intelligence of the children.

(4) The influence of overcrowding, bad economic condition of the home, moral and physical condition of the parents on the intelligence, eyesight, glands, and hearing of the children. 
In our investigation of the first and third points we are fortunate enough to possess in each case two distinct sets of statistics, so I feel I can speak with greater confidence of the results.

In the other two cases we are dependent on one set of statistics in each case; for the influence of the occupation of the father we have the Glasgow School Board statistics, and for the effect of environment on intelligence, eyesight, \&c. we have the Report of the Edinburgh C.O.S.

We will first examine the results that have been found for the correlation between the employment of mothers and the height and weight of their sons; and we must ask the reader to keep in mind our problem, namely: Are the physical and mental characters of children correlated with their or their parents' environment to a higher, an equal, or a lesser extent than they are correlated with their parents' physical and mental characters?

The larger series of statistics from Glasgow is not really so satisfactory as one might at first sight suppose, as it appears that comparatively few married women in Glasgow have other than the customary domestic work of their homes.

Dr Leslie Mackenzie, in his report on these statistics, divides the schools into four groups according to the districts in which the schools are situated, and we have kept to these groups in working out the correlation coefficients-but have also worked the coefficients for all schools taken together.

Group A comprises schools in the poorest districts of the city.

Group B comprises schools in poor districts.

Group C comprises schools in districts of a better class.

Group D comprises schools in districts of a still higher class, and includes four out of five Higher Grade Schools.

What then is the effect of the employment of the mother on the height and weight of her sons in Glasgow and in Edinburgh?

In the Introductory Note to the C.O.S. Report of the Edinburgh children it is stated that the children come from a school in the poorest part of the city, but that this school also has an admixture of the children of the comfortable and respectable working class.

Table I gives the correlation coefficients for the effect of the employment of mothers on the weight and height of their sons, and we notice:

(I) That the employment of mothers is correlated to a small extent with lesser weight of their sons, the coefficient being $\cdot 12$ for 
all schools in Glasgow and - It for Edinburgh, and we may say that the results obtained from the two distinct sets of statistics are well in agreement.

TABLE I.

Partial Correlation Cocfficients of Employment of Mother and Physique of Children for Constant Age of Child.

Influence of the Employment of Mothers on the Physique of her children

\begin{tabular}{|c|c|c|c|c|c|c|c|}
\hline & \multicolumn{2}{|c|}{ Sons } & \multicolumn{2}{|c|}{ Daughters } & \multicolumn{3}{|c|}{$\begin{array}{l}\text { Influence of } \\
\text { Heredity }\end{array}$} \\
\hline & Weight & Height & Weight & Height & & & \\
\hline Glasgow & & & & & \multicolumn{3}{|c|}{ Stature : Mother and } \\
\hline $\overrightarrow{8}$ & $\begin{array}{l}.00 \\
.12\end{array}$ & $\begin{array}{l}11 \\
\cdot 15\end{array}$ & $\begin{array}{l}.03 \\
.11\end{array}$ & $\begin{array}{l}.08 \\
.16\end{array}$ & \multirow{2}{*}{, } & Son I & 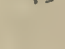 \\
\hline 造 C & - I I & .19 & - II & -19 & & Daughter & $\cdot 5 I$ \\
\hline 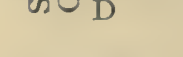 & - I I & -I 7 & .09 & - 12 & \multicolumn{2}{|c|}{ Eye-colour: Parental } & 49 \\
\hline All Glasgow & $\cdot 12$ & $\cdot 20$ & - Io & .02 & & Parental $\}$ & $\cdot 32$ \\
\hline Edinburgh & $\cdot 14$ & .09 & .02 & .00 & $"$ & $\left.\begin{array}{l}\text { Grand } \\
\text { Parental }\end{array}\right\}$ & $\cdot 19$ \\
\hline
\end{tabular}

(2) That the employment of mothers is also correlated with lesser height of sons, and that this correlation is somewhat larger than that found for weight in Glasgow. The effect of the employment of mothers on the height of sons in Edinburgh is measured by the coefficient 09 , which is distinctly lower than that found for all Glasgow. The Edinburgh schools are, however, probably closest in grade to the Glasgow Group A.

(3) That there is a distinct difference in the correlation coefficients in the different school groups in Glasgow. This is not what we should expect if the population were homogeneous, and leads one to hold that some special influence must be at work which has lowered the correlation in the worst school group or raised it in the better school groups. Taking into consideration the value found for the Edinburgh schools we should be inclined to think that some racial factor we have not yet measured has artificially raised the coefficient in the better school groups. 
We must next compare the influence of the employment of the mother on the physique of her son with the hereditary influence of the actual height of the mother on the height of her son. This hereditary influence is given in Table I for the sake of comparison. The effect of inheritance of stature of mother and son is measured by the coefficient *49. The coefficients for eye-colour for the parental, grandparental, and great grandparental relationships are also given, and it will be noticed that the only value at all comparable with the environmental values is that found for great grandparents, which is about equal to that found for the effect of mothers' employment on sons' height in Glasgow, but distinctly higher than the other correlation coefficients. We cannot help being struck by the comparative unimportance of, at any rate, one environmental factor as compared with the heredity factor.

We will add one further remark on the differences we have found in the correlations between employment of the mother and height of her sons in Glasgow. In Glasgow the values found range from - I to $\cdot 2$. At present we have no final explanation beyond heterogeneity for this result. But we would mention a fact noted by Dr Tocher in a paper on the pigmentation survey of Scotland, published in Biometrika, vol. vI, pp. I29-235. In that paper Dr Tocher calls attention to the large foreign element in Glasgow as judged by the names of the children and confirmed by their hair and eye-colour. There are a large number of Jews, especially in Groups B and C, and a fairly large proportion of Irish in the schools in Group D. Can mixture of races account for the higher correlations in some of the Glasgow groups ${ }^{1}$ ?

Future investigations will show whether the influence of the mother's employment on the height of her sons is greater than (as apparently in Glasgow) or less than (as apparently in Edinburgh) the influence of her employment on the weight, and whether the influence of employment on height is represented by the higher or lower correlation coefficient, by $\cdot 2$ or by $\cdot I$. At present we must content ourselves with saying that the connection between the employment of the mother and the weight of her sons is about $\cdot 12$, and that the connection between the employment of the mother and the height of her sons is between $\cdot I$ and $\cdot 2$. Taking into consideration the result

1 If we compare the mean height and weight of the Edinburgh boys with those of boys in the different school groups at Glasgow, we find that they lie between the Glasgow groups A and B, just where the correlation coefficients fall. Thus the Edinburgh and Glasgow values may not be really contradictory. 
found in the worst school group we are inclined to think that the lower value is the more correct.

Even if the higher value proves to be the true one, $\cdot 20$ is still a low correlation, and when we remember that the value for the correlation coefficient of heredity between height of mother and son is 49 we see that employment of the mother has far less influence than heredity on the physique of the son.

We now turn to the correlation between the employment of the mother and the height and weight of her daughters. In the Edinburgh schools we see that there is practically no connection between employment of the mother and the physique of her daughters; the correlation coefficients are $\cdot 02$ and $\cdot 00$. When we examine the results for Glasgow we see that the effect of the mother's employment on the weight of her daughters is very uniform in the three school Groups B, C, D, namely -II, II and $\cdot 09$, and is about the same as the effect on the weight of the sons; it is insignificant in the worst class, Group D, of schools. The height results are again more irregular, varying from $\cdot 08$ to $\cdot 19$, but when we take the data for all Glasgow the correlation is insensible; it would seem that the height of girls is less affected by the mother's employment than the height of boys, and the result for all Glasgow agrees with the result found for Edinburgh.

The results we have reached show on the whole that the employment of the mother has even less influence on the physique of her daughters than on the physique of her sons.

Employment of the mothers then is associated to a small extent with lighter weight and shorter stature of their sons, but we are not sure that even the small association we find is necessarily a true measure of cause and effect. There are secondary obscuring effects of heredity. The weaker and more delicate mothers may not seek external employment, and naturally they would have weaker children. This lowers the association. Furthermore, inferior physique in the fathers may be a reason for the necessity of the mother's work. This would raise the association. We know from the C.O.S. report that the mother's work is associated with a lower rate of wage of the father-the average wage of the husband of an unemployed woman is $26 \mathrm{~s} .2 d$. and of an employed woman is $22 \mathrm{~s}$. II $d$. It seems reasonable to suppose that a man of inferior physique may have to take a lower wage, and thus it is his wife who will be obliged to work. Now if the husbands of these working women are physically weaker than other husbands we should expect their sons to be shorter and lighter than 
other persons' sons, whether the mother worked or not. We want to know the height and weight of the husbands of employed and unemployed mothers before we can be sure what proportion of the correlation we see between the mother's employment and son's height and weight is due actually to the mother's work and what is really due to the less weight and height of the fathers. We quite realize that we may find low wages do not depend on the physique of a workman at all, but, if they do, then some of the apparent result on the child of the mother's work will probably be due to the inferior physique of her husband.

There is another point in this connection we should like to mention. If employment of mothers has a bad effect on their sons, either directly before birth or indirectly owing to less home care, there ought to be less bad effect when the mother only works out part of the day than when she works out the whole of the day; but this is not the case, at least it is not the case in Edinburgh in those families investigated by the C.O.S. From this report we are able to divide the mothers into four classes: (I) those who do no work beyond their domestic duties, (2) those who work in their homes, (3) those who work out part of their time, (4) those who work out the whole of their time.

Weight of Boys at a Constant Age.

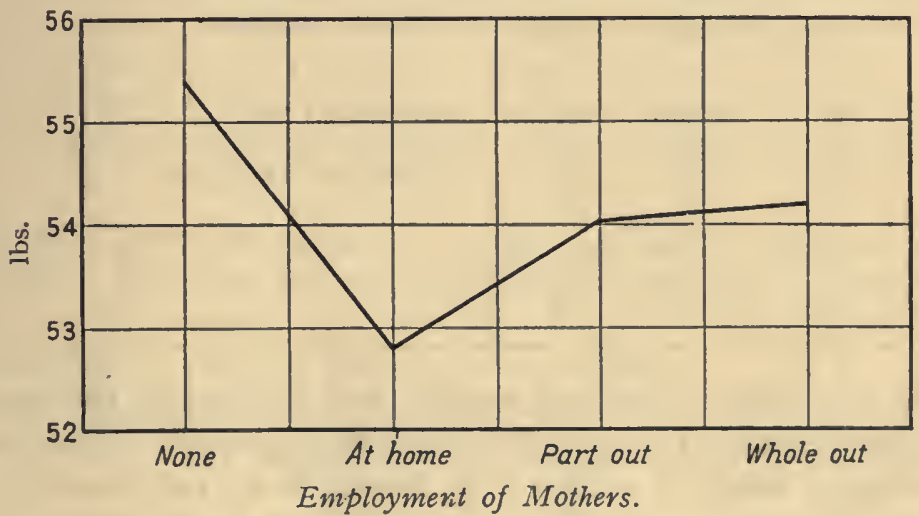

The diagram shows the average weight of the boys for a constant age, i.e. the mean age 9.6 years. The mean weight of the boys is practically identical whether the mother works out all or only part of the time.

When the mother works "in" the weight of the boys is lqwest, but there are only $3 \mathrm{r}$ cases, so we can lay no stress on this result; 
the mother works out part of the time in 129 , and the whole time in 79 cases, which are more reasonable numbers on which to base a conclusion.

We must now turn to the second problem under consideration, i.e. the influence of the occupation of the father on the physique of his sons. Unhealthy trades have been considered largely responsible for physical unfitness in the children. After some consideration we decided to measure the unhealthiness of a trade by the annual deathrate per 1000 living in the different trades between the ages 25 and 45. These numbers were taken from the Registrar General's returns for Scotland, and range from 3 per thousand for ministers and gamekeepers to I 8 per thousand among barmen, cellarmen and general labourers. The classification is not by any means perfect but, though rough, it gives a fairly satisfactory estimate of the healthiness or unhealthiness of a trade.

TABLE II.

Low Mortality Rate of Fathers and Greater Height and Weight of Sons.

\begin{tabular}{|c|c|c|c|c|}
\hline & & & \multicolumn{2}{|c|}{ Influence of Heredity } \\
\hline Schools & Weight & Height & \multicolumn{2}{|l|}{ Stature } \\
\hline$\stackrel{\mathrm{A}}{\mathrm{B}}$ & .09 & - I 2 & \multirow{3}{*}{$\begin{array}{l}\text { Father and Son } \\
\text { Father and Daughter }\end{array}$} & $\cdot 5 \mathrm{I}$ \\
\hline $\mathrm{C}$ & .03 & .05 & & \multirow[t]{2}{*}{51} \\
\hline $\mathrm{D}$ & .OI & .02 & & \\
\hline All & .09 & $\cdot 12$ & 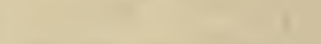 & \\
\hline
\end{tabular}

Here the results are very regular and practically the same for height and weight. There is a certain very slight association between the unhealthy trade of a father, as measured by the mortality rate, and inferior physique in his children in the worst school group, but it becomes practically nil in the better school groups. We must again notice the low value of the correlation coefficient when we compare it with the value found for the correlation between height of father and son. And in this case also we must point out that we do not know how much of this apparent association is due indirectly to heredity, 
and to the probable fact that on the whole weaklings are driven into less desirable occupations. A man who is physically unfit has to work for any employer who will take him, and we shall probably frequently find him doing casual labour or working in a factory where little bodily strength is required. Here again we need the average height and weight of the fathers of all these sons to see whether fathers in a trade with a low mortality rate are taller and heavier than fathers in a trade with a high mortality rate. Is the casual labourer with a mortality rate of 18 per thousand lighter and shorter than the carter with a mortality rate of 8 per thousand? the factory hand with a mortality rate of $\mathrm{I} 3$ per thousand than the blacksmith with a mortality rate of 7 per thousand? If so, children of the casual labourer or the factory hand will be lighter and shorter than the children of the carter or blacksmith, quite apart from any direct influence of unhealthy employment of the parent.

In the Appendix to the Report of the Royal Commission on Physical Training a table is given showing the average stature of men at all ages, divided into four classes according to their occupations. These do not correspond exactly with our mortality rates, but they do so roughly and are therefore of interest.

Class I includes farmers, clergy, lawyers, doctors, teachers, architects, \&c. ; all these have a mortality rate of between 3 and 6 per 1000 and come in our mortality groups $3,4,5$ and 6 , except doctors, who are in our group 9.

Class II includes law clerks, shop-keepers, dealers in drugs, books, food, drinks, \&c., and the majority come in our mortality groups 7 and 8 .

Class III includes gardeners, railway and quarry workers, sailors, miners, \&c. ; these also are mostly included in the groups with mortality rates 7 and 8 but they vary more than Class II. The mortality rates of Classes II and III are, however, very similar.

Class IV includes workers in metal and stone, engravers, printers, \&c. who are mostly included in the groups with mortality rates 9 and Io.

The mortality rates then roughly correspond with these classesthat is to say-

Class I includes occupations with the lowest mortality rates 3 and 6.

Classes II and III include occupations with higher mortality rates 7 and 8. 
Class IV includes occupations with still higher rates 9 and ro. The next table gives the mean height and weight for each class.

TABLE III.

\begin{tabular}{|c|c|c|c|c|}
\hline & Class I & Class II & Class III & Class IV \\
\hline $\begin{array}{l}\text { Height } \\
\text { Weight }\end{array}$ & $\begin{array}{r}69.4 \text { ins. } \\
168.4 \text { lbs. }\end{array}$ & $\begin{array}{r}67 \cdot 9 \\
157 \cdot 0\end{array}$ & $\begin{array}{r}67 \cdot 5 \\
157 \cdot 5\end{array}$ & $\begin{array}{r}66 \cdot 7 \\
147 \cdot 9\end{array}$ \\
\hline
\end{tabular}

We see then that men occupied in a trade with a lower mortality rate are heavier and taller than men in a trade with a higher mortality rate, which suggests that the very small correlation we have found between unhealthiness of the father's trade and the height and weight of his sons is not all due to the unhealthiness of the trade, but is due at least, in part, to the inferior physique of the father. In fact we have very little hesitation in saying that unhealthiness of a trade of a father has small influence on the physique of his sons, and that it is because men of inferior physique are forced into worse trades that we see this apparent slight connection.

We now turn to the question of drink and shall measure its effect on the height, weight, general health and intelligence of the children. More disastrous results have been attributed to drink than to any other social evil-we might almost say than to all other social evils taken together. Since we have been working at this subject we have read carefully many speeches, as reported in the papers, on the subject of drink, and confess we have been somewhat astonished at the statements occasionally made.

For example: a well-known man is reported to have said in the course of a speech enumerating the various evils resulting from drink that $10 \%$ of the children of drunkards are tuberculous, but he made no mention of the fact that practically ro $\%$ of the general population suffer at one or another period from tuberculosis.

We do not say that alcoholism and tuberculosis are not associated, it is quite possible they may be, but a statement such as that we have quoted proves nothing of the sort, and is entirely misleading unless we are told at the same time the percentage of the tuberculous in the same class of the general population, which in this case was not stated.

We have two series of statistics for studying the question of the 
effect of drink, the Edinburgh Charity Organization Society Report and the statistics provided for us by Miss Dendy.

We will consider first the results obtained from the Edinburgh statistics, which are given in the next table.

TABLE IV.

\begin{tabular}{l|c|c|c}
\hline & $\begin{array}{c}\text { Drink and } \\
\text { Weight }\end{array}$ & $\begin{array}{c}\text { Drink and } \\
\text { Height }\end{array}$ & $\begin{array}{c}\text { Drink and } \\
\text { Intelligence }\end{array}$ \\
\hline Boys & .05 & .04 & -.03 \\
Girls & .08 & .09 & .00 \\
\hline
\end{tabular}

Here we see that drink in the parents has no effect on the intelligence of boys or girls, and practically none on the height and weight of boys. In the case of girls there is a very slight correlation between drinking of the parents and lower weight and height in the daughters, but considering that the probable error of these results is about $\cdot 03$ they are only just significant. Is this slight difference between the effect of drink on boys and girls due to the possibility that when the mother drinks the girls have to look after the home, whereas the responsibilities of the boys are not increased? But, whatever the reason, we would emphasize the fact that a correlation of .09 is of very little importance as compared with a correlation of 50 due to heredity.

Before considering these results further we may turn to the statistics obtained from the special schools in Manchester. Here we

TABLE V.

\begin{tabular}{l|c|c|c|c}
\hline & \multicolumn{2}{|c|}{ Father } & \multicolumn{2}{|c}{ Mother } \\
\cline { 2 - 4 } & $\begin{array}{c}\text { Intemperance } \\
\text { and } \\
\text { Health }\end{array}$ & $\begin{array}{c}\text { Intemperance } \\
\text { and } \\
\text { Intelligence }\end{array}$ & $\begin{array}{c}\text { Intemperance } \\
\text { and } \\
\text { Health }\end{array}$ & $\begin{array}{c}\text { Intemperance } \\
\text { and } \\
\text { Intelligence }\end{array}$ \\
\hline $\begin{array}{l}\text { Sons } \\
\text { Daughters }\end{array}$ & -.06 & -.04 & -.07 & -01 \\
-.04 & -.02 & -.03 & -.08 \\
\hline
\end{tabular}

cannot find the correlation coefficients between drink and actual height and weight of the children, but we can find the coefficient of correlation between drink and general health, and between drink and 
intelligence. In this case we have worked out the influence of the drinking of ( 1 ) the father, (2) the mother, on the health and intelligence of the children.

Here again we see that drink has practically no influence on the general health and intelligence of boys and girls, and the little influence it has is in favour of the children of drinking parents, they are healthier and more intelligent. These results are certainly startling and rather upset one's preconceived ideas, but it is perhaps a consolation that to the obvious and visible miseries of the children arising from drink, lowered intelligence and physique are not added.

But before asserting that intemperance of the parents has practically no effect on the physique and intelligence of the children, there is a point to be considered which we mentioned in the first part of this paper. What is the status of the drinking workman? Is the drinker on an average the abler man and of finer physique? If so, his children should show greater ability and better physique than the children of the non-drinking parent, and further, if the abler workman get higher wages, and thus notwithstanding drink, the food at home has been of better quality, we should expect his children to be better developed physically than those of the non-drinker.

As before the only estimate we have at present of the intelligence and physique of a workman is the wage he earns. A high wage on an average will mean a stronger and more efficient workman. We want to discover therefore whether drink and good wage go together to any large extent. If they do, then drinking fathers should have stronger and more intelligent children than non-drinking fathers. But unless there is a fairly well marked correlation it will not be sufficient to affect greatly our results.

We divided parents into three classes: (I) both parents drink, (2) one parent drinks, (3) neither parent drinks, and the wages into four groups: (I) under I8s. a week, (2) I $8 s$. - 24s. inclusive, (3) $26 s$. to $34 s .,(4) 36 s$. and over $36 s$. The correlation coefficient found by the fourfold method between the drinking of one or both parents and a high wage is $\cdot 03$, which means that there is practically no connection between drinking of the parents and a high wage. The means show the same thing-the mean wage when both parents drink is $24 s .8 d$., when one parent drinks is $25 s .6 d$., and when neither parent drinks is $25 s$. 5 d. - there is a slightly lower wage when both parents drink and a very slightly higher when one parent drinks, but we cannot attach any importance to a difference of $I d$. We tried to find from 
the Manchester special schools what was the connection between wages and drink, but the wages are very seldom given when the father drinks. From the few cases where they are given I found the average wage of a drinking father to be $23 s .7 d$., and of a non-drinking father to be $23 s .4 d$., i.e. a slightly higher wage for the drinking father in Manchester, but the numbers are too few for the results to be considered of any importance. If wage then is an estimate of ability and physique we may say that the ability and physique of the drinking workman is about the average, and we can state with greater confidence that the "well-known fact" that drinking has a bad effect on the physique and intelligence of the children has yet to be proved.

The whole subject of the influence of environment, owing to its complexity, is a fascinating one, partly because we are only just beginning to apply modern statistical methods to this side of eugenics, and the results we obtain are often very unexpected, perhaps we may say wholly contrary to current belief.

The fact that our conclusions as to the comparative unimportance of the environment factors of employment of mothers, occupation of fathers and drink of the parents are contrary to preconceived opinions, makes more work and more statistics. on this side of eugenics most necessary.

We now come to the last point under consideration-the effect of the home environment on the intelligence, eyesight, glands and hearing of the children. The statistics being taken from the C.O.S. Report. The home environment factors we have chosen are:

(a) The number of people per room of the home. Unfortunately we do not know the, size of the rooms, but in a general way we have a measure of the space in the home by considering the number of people per room.

(b) Economic condition of the home. We divided the homes into "good" and "bad" from a consideration of the information given in the C.O.S. "Summary of Facts," and took into account also the cleanliness of the children, regularity of attendance, \&c.

(c) Physical condition of the parents. The Report states if the parents are broken down in health or suffer from tuberculosis, \&c., persistent alcoholism was included in bad physique.

(d) Moral condition of the parents. The chief difficulty was to decide how far alcoholism is to be treated as a moral complaint.

Generally speaking we placed the heavy drinker in the category of moral failure when the drinking was accompanied by "conviction for brutal assault on wife," "house a regular brothel," frequent convictions 
for being drunk and disorderly. Drinking is so prevalent that it is impossible to take it as determining in itself bad moral conditions. "Man a good workman, but goes on spree from time to time, is in two thrift clubs and attends church," or "old soldier and widower who takes a nip now and then, but is good to his girls-very nice, tidy, clean people," can hardly suffice for placing the described in the category of moral failure. On the other hand "Very dirty, untidy home...Man teetotal, keeps well at his work...China and clothes lying piled about room, thick with dust; air very bad. Children sickly (eldest imbecile); wife a slattern," seems to be a case where there is a moral deficiency likely to affect the condition of the children.

In each case we have had to trust to personal judgment, and though we think we should put the bulk of the cases in the same classes if we went through the book a second time, it is possible that in some doubtful cases our judgment would not be the same. The negative sign when it occurs means that the worse environment is associated with the better condition in the children.

Let us consider the results collected in Table VI.

TABLE VI.

Effect of Home Environment on Sight, Intelligence, Glands, Hearing.

\begin{tabular}{|c|c|c|c|c|c|c|}
\hline \multirow[t]{2}{*}{$x$} & \multicolumn{2}{|c|}{ Refraction } & \multicolumn{2}{|c|}{$\begin{array}{c}\text { Keenness of } \\
\text { Vision }\end{array}$} & \multicolumn{2}{|c|}{ Intelligence } \\
\hline & Boys & Girls & Boys & Girls & Boys & Girls \\
\hline \multirow[t]{3}{*}{$\begin{array}{l}\text { No. of people per room ............ } \\
\text { Good Economic conditions ...... } \\
\text { Good Physical condition of Parents } \\
\text { Good Moral condition of Parents }\end{array}$} & $\begin{array}{l}-\cdot 00 \\
+\cdot 03 \\
-\cdot 00 \\
-\cdot 14\end{array}$ & $\begin{array}{l}-\cdot 15 \\
-\cdot 12 \\
+\cdot 00 \\
-\cdot 05\end{array}$ & $\begin{array}{l}-\cdot 06 \\
-\cdot 00 \\
-\cdot 00 \\
-\cdot 10\end{array}$ & $\begin{array}{l}-\cdot 14 \\
-\cdot 01 \\
+\cdot 00 \\
+\cdot 06\end{array}$ & $\begin{array}{r}.02 \\
\cdot 10 \\
-\cdot 04 \\
-\cdot 07\end{array}$ & $\begin{array}{l}.04 \\
.16 \\
.06 \\
.03\end{array}$ \\
\hline & \multicolumn{2}{|c|}{ Glands } & \multicolumn{2}{|c|}{$\begin{array}{l}\text { Keenness of } \\
\text { Hearing }\end{array}$} & \multicolumn{2}{|c|}{$\begin{array}{c}\text { Diseases of } \\
\text { Ear }\end{array}$} \\
\hline & Boys & Girls & Boys & Girls & Boys & Girls \\
\hline $\begin{array}{l}\text { No. of people per room ......... } \\
\text { Good Economic conditions } \ldots \ldots . . \\
\text { rood Physical condition of Parents } \\
\text { Good Moral condition of Parents }\end{array}$ & $\begin{array}{l}.02 \\
.06 \\
.05 \\
.02\end{array}$ & $\begin{array}{r}-.01 \\
.03 \\
\cdot 06 \\
\cdot 02\end{array}$ & $\begin{array}{r}-\cdot 07 \\
\cdot 05 \\
\cdot 13 \\
\cdot 10\end{array}$ & $\begin{array}{l}\cdot 00 \\
.08 \\
.00 \\
.06\end{array}$ & $\begin{array}{r}.02 \\
.02 \\
-.01 \\
\cdot 08\end{array}$ & $\begin{array}{l}\cdot 07 \\
\cdot 14 \\
\cdot 01 \\
\cdot 08\end{array}$ \\
\hline
\end{tabular}


The eyesight results are already published in a memoir by Amy Barrington and Karl Pearson. Normal vision is on the whole slightly associated with overcrowding, bad economic conditions and morally defective parentage. Can it be that these home conditions keep the children in the streets, and so relatively away from bad environment and in relatively fresher air? Whatever may be the cause the Edinburgh statistics show that the effect of home influence is not one-tenth that of heredity, and what exists, if it be appreciable at all, is in the opposite direction from what we should have anticipated. Intelligence is slightly associated with few people per room and with a good economic condition in the home for boys and girls, though for boys it is scarcely appreciable; it is also associated for girls very slightly with good physical and moral condition in the parents, but for boys we get better intelligence in the children associated with bad physical and moral condition in the parents.

Glands and hearing tell the same tale. There is only a slight connection between the presence of swollen glands or bad hearing and bad environmental conditions. All the coefficients are small and irregular, some scarcely appreciable, but in most cases they are positive, i.e. better physique goes with better environment, though it is but in a weak degree ${ }^{\mathbf{1}}$.

Such a table as that on p. 20 , indicating in many directions the relative insignificance of nurture in influencing man's welfare, gives us reason to pause when we consider the methods of modern social reform.

The question of the respective influences of heredity and environment is becoming one of vital importance. It seems only too true at the present time that the physically and mentally weaker stocks are reproducing themselves at a greater rate than those of sounder physique and intelligence.

This, unchanged, must mean that the average physique and ability of our nation as a whole will decline and must decline unless we can prove that by a better environment we can raise the level of the community. So far as our investigations have gone at present they show clearly the small influence of environment; work of the mother,

1 Heredity as before plays far the larger part. The measure of the inheritance of eyesight is equal to that found for other physical characters and the same is true of intelligence (*49). Recent work of the Laboratory (British Medical Journal, July 20, 1909: see Appendix to this Lecture) shows that environmental conditions can hardly be the chief source of eye-disease. The correlations are low and more often negative than in the case of ear-disease. 
an unhealthy trade of the father and the drinking of the parents seem to have very little influence on the physique of the children. Overcrowding, bad economic conditions, bad physical and moral conditions of the parents have practically no effect on the intelligence, eyesight, glands and hearing of the children. It is possible that better measurements of environmental characters than we yet possess may show more correlation, and it is also possible that other characters may prove more influential. But so far as our researches reach we think we have shown that it is quite easy to demonstrate a large hereditary factor, and it is not at all an easy thing to show that any of the environmental factors we have measured up to the present time have any important effect on the children. Not only are the correlations low but we have reason to think that such small correlations as exist may be secondary results of racial or hereditary influences.

Practically all social legislation has been based on the assumption that better environment meant race progress, whereas the link between the two is probably that a genuine race progress will result in a better environment. The views of philanthropists and of those who insist that the race can be substantially bettered by changed environment appeal to our sympathies, but these reformers have yet to prove their creed. As far as our investigations have yet gone they show that improvement in social conditions will not compensate for a bad hereditary influence; the problem of physical and mental degeneration cannot be solved by preventing mothers from working, by closing public-houses, or by erecting model dwellings. The only way to keep a nation strong mentally and physically is to see to it that each new generation is derived chiefly from the fitter members of the generation before. 


\title{
APPENDIX $\mathrm{A}^{1}$ \\ HOME CONDITIONS AND EYESIGHT
}

\author{
By Karl Pearson, F.R.S.
}

It may not be without interest, in view of recent criticisms of a memoir by Miss Barrington and myself ${ }^{2}$, to publish some further determinations of the relation of home conditions to sight.

Before doing so it will be well to point out one or two important considerations which I think have considerable bearing on the manner in which statistics ought to be collected, having regard to the medical inspection of school children, which is now becoming universal.

The first point I would insist upon is that careful distinction must be made between $(a)$ home environment and (b) school environment.

Our'paper dealt chiefly with the influence of home environment on both refraction and acuity of vision. Now, as far as I am aware, the only material hitherto available for testing the influence of the actual home conditions on the presence of eye disease, on the goodness or badness of vision, or on shortsightedness, is that provided by the report of the Edinburgh Charity Organization Committee, where we have for the first time the sociological report on the home conditions placed alongside the ophthalmological report on the child's eyes, and accompanied in each case by the age of the child. I do not see how it is possible without such information to draw conclusions as to whether the home conditions do or do not affect sight. I am quite prepared to be shcwn that the conditions in Edinburgh are exceptional, but the proof can only be given when the children who are reported on elsewhere are followed up into their-homes, and the state of these is recorded, as in the Edinburgh investigation.

Further, the Edinburgh material was of special value, because there is not the same extraordinary mixture of racial types in that city which is to be found in Glasgow or London. We are told, for example, that Russian Jews have in London a very high percentage of eye defect. Any one who has studied the copious statistics of Randal must be convinced that the degree and extent of myopia is markedly a racial character ${ }^{3}$. Those who have investigated any

1 Reprinted by kind permission from the British Medical Journal, July I7, 1909.

2 Eugenics Laboratory Memoirs, No. v, "A First Study of Vision and of the Relative Influence of Heredity and Environment on Sight." Cambridge University Press.

3he Jews, like the Germans, are largely brachycephalic, and the increasing brachycephaly of the town populations is a point not without suggestiveness for changes in eyesight. 
local group in this country know that in anthropometric characters it is usually significantly differentiated from any other local group. The population of our suburbs is usually more sedentary than the population in the working class districts of the town itself and less mixed.

I know, as a matter of fact, that the cephalic index of school children varies very sensibly from one district of London to a second. On this ground alone it is not possible, without control measurements, to assert that, because the percentage of eye defect varies from Whitechapel to Hampstead, the result is due to home environment. It may be so, but a mere statement of percentages in different districts without (a) age distributions, (b) racial proportions, and (c) percentages of defective parents in each district, will not convince those who desire logical statistical proof before forming any conclusion. It is well known that the defective parents also gravitate to the worst districts, and we may expect the defective children there also. For these reasons the work at Edinburgh was especially valuable. It gave age distribution, it dealt with a racially fairly homogeneous material, and it followed up the children into their homes and told us something, if not all we might desire to know, about their parents. I see no other way in which a real solution could be obtained for London. An individual school or two must have all-not only the defectivechildren examined, and the eyesight report must be accompanied by a sociological report.

A report such as that of Dr A. Hugh Thompson on the London school children, in which the numbers at each age of both the normal and the defective children are not given, cannot help the statistician in the least to arrive at definite results. Nor, unless the children are followed into their own homes, is it even possible to say how far bad food, bad air, or parental neglect may account for the presence of any disease. There is always the diathesis as a contributory source, and the fact that all the children in the same family may not be attacked, shows that the variability within the family also plays its part.

Again my critics will, I hope, pardon me if I say that I am not convinced when I am asked whether this or that "is not a fact." For example, whether it is not a fact that in the better homes the children are more studious, or that the more respectable parents keep their children at home. Either may be the truth, but what we want.are actual numerical measures of the effect of these supposed causes in invalidating the apparently small influence of the environmental as compared with the hereditary factor.

What we want are more data before we conclude that results are paradoxes because of such or such an explanation being "a fact" or "a matter of common experience."

Let us attempt to get any information we can on the problem of whether the better class parents keep their children at home, and so their offspring are more studious and suffer more from myopia ${ }^{1}$. Now, I know of no statistics which at all touch this point of the studious character of the offspring of better

1 The reader of our memoir will remember that our conclusion was, not that the better homes produced more myopia, but that there was no marked relationship between bad homes and defective sight. 
class parents, but I suppose the argument to be that the children are kept more at close work and that this damages their sight. Now, it would be possible to compare the sight of children of the same age who came to school at different ages originally, and thus find out whether those who began to read earlier have markedly worse sight. It would be very desirable to collect statistics de novo on this point. The only material that I know of bearing on the subject is that used by Miss Barrington and myself, and provided by Cohn, who gives the correlation tables of sight and years of school life, and sight and age. We have shown that the relationship is more intimate between sight and age than between sight and years of school life, and that, considering the high correlation of years of school life and years of age, the latter is most probably only a derived result of the former. Now, we have recently re-worked Cohn's data and discovered the correlation between the ages at which the child began to read and the degree of myopia at a constant age. The partial correlation coefficient is:

$0.0_{4}$, if age and length of school life have a correlation of 0.8

0.13 , if age and length of school life have a correlation of 0.9 .

Now it will, perhaps, be said that the latter is a quite sensible correlation, but compare it with the heredity correlations of 0.40 to 0.60 , and we see that environment is quite overmastered by heredity. Furthermore, the correlation has the wrong sense, the later the child went to school, the worse at a given age is the myopia. I have little doubt that the correlation in this case is sensibly zero, or the age at starting reading has little influence on the result. Cohn's statistics are, of course, not final, but they are very suggestive, because they have hitherto been supposed to prove the exact reverse of what is really extractable from them.

I now turn to the question of the effect of good or bad home environment on disease of the eye. I will consider first corneal nebula and illustrate by some of the percentages:

Percentages of Corneal Nebula.

\begin{tabular}{|c|c|c|c|c|}
\hline \multirow{2}{*}{ Feature of the Home Estimated } & \multicolumn{2}{|c|}{ Boys } & \multicolumn{2}{|c|}{ Girls } \\
\hline & Good & $\mathrm{Bad}$ & Good & $\mathrm{Bad}$ \\
\hline 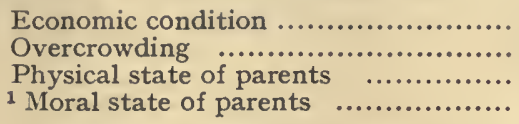 & $\begin{array}{l}3 \cdot 6 \\
2 \cdot 5 \\
3 \cdot 8 \\
3 \cdot 5\end{array}$ & $\begin{array}{l}2 \cdot 3 \\
3 \cdot 3 \\
2 \cdot 5 \\
2 \cdot 5\end{array}$ & $\begin{array}{l}3 \cdot 9 \\
2 \cdot 5 \\
3 \cdot 1 \\
2 \cdot 5\end{array}$ & $\begin{array}{l}2 \cdot 2 \\
3 \cdot 4 \\
2 \cdot 8 \\
3 \cdot 5\end{array}$ \\
\hline Means................... & $3 \cdot 35$ & $2 \cdot 65$ & $3 \cdot 00$ & 3.00 \\
\hline
\end{tabular}

1 This category should a priori be considered the most important one in this matter. It marks essentially neglect of the children. Where the home is practically a brothel or the parents habitual drunkards there can be no proper cleanliness or care of offspring. 
Now it is extraordinarily difficult to lay any stress on results whose differences are of this order. A bad moral state of parents would be interpreted to mean less corneal nebula for the boys and more for the girls, the percentages being just reversed. Good economic conditions in both boys and girls would mean 1.5 per cent. more of the disease, and so would the good physical condition of the parents. In such circumstances what stress can be laid on the 0.8 per cent. difference between crowded and non-crowded homes? The only safe conclusion to be drawn is that in Edinburgh at least there is no marked relationship between corneal nebula and bad home environment. The curious point is that if we take all diseases of the eye and eyelid, we appear to get a slightly more definite, but still a quite negligible relation between lisease and home environment. A difficulty is whether to include strabismus or not; the correlations have been worked out by E.thel M. Flderton, of the Eugenics Laboratory, including and excluding "squiut." In-each a positive correlation means that there is more eye disease with the worse home condition.

Percentages of all Eye Diseases.

\begin{tabular}{|c|c|c|c|c|}
\hline \multirow{2}{*}{ Feature of the Home Estimated } & \multicolumn{2}{|c|}{ Boys } & \multicolumn{2}{|c|}{ Girls } \\
\hline & $\begin{array}{l}\text { With } \\
\text { Squint }\end{array}$ & $\begin{array}{l}\text { With- } \\
\text { out }\end{array}$ & $\begin{array}{l}\text { With } \\
\text { Squint }\end{array}$ & $\begin{array}{l}\text { With- } \\
\text { out }\end{array}$ \\
\hline 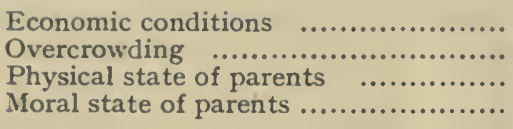 & $\begin{array}{r}0.10 \\
0.05 \\
-0.02 \\
0.04\end{array}$ & $\begin{array}{r}0.14 \\
0.08 \\
-0.02 \\
0.03\end{array}$ & $\begin{array}{r}-0.03 \\
0.04 \\
-0.10 \\
-0.01\end{array}$ & $\begin{array}{r}0.02 \\
0.12 \\
-0.15 \\
0.01\end{array}$ \\
\hline
\end{tabular}

Now, it is quite impossible to lay any stress on these results. Six ont of the 16 show less disease with worse home conditions, and if we have positive correlations of O.IO and O.I4, we have negatives of -0.10 and -0.15 . Further, no correlation of this kind lying under about 0.25 can be really considered to have definite importance. How very different these values are from the values running from 0.4 to 0.6 found in our memoir for the inheritance factor in eyesight!

It is worth while putting on record here the quantitative contributions of refraction and diseases of the eye in producing defective vision. The refraction results are taken from our memoir; the disease results have been recently worked out by Ethel M. Elderton.

\begin{tabular}{c|c|c|c}
\hline & $\begin{array}{c}\text { Keenness of Vision } \\
\text { and Refraction } \\
\text { (Contingency) }\end{array}$ & \multicolumn{2}{|c}{ Keenness of Vision and Disease } \\
\cline { 3 - 4 } & $\begin{array}{c}\text { Squint included } \\
\text { Boys ..... }\end{array}$ & Without squint \\
\hline Girls ..... & 0.58 & 0.36 & 0.21 \\
\hline
\end{tabular}


It will be seen that, if we exclude strabismus, the diseases of eye and eyelid do not produce half the effect on vision that refraction does.

Now I do not intend to argue for a moment that the Edinburgh data provide the final word in these matters, but they form the first solid attempt to provide information as to the influence of home environment. Neither the school medical officer nor, as a rule, the teacher can follow the children into their homes. All that has hitherto been done has been more or less plausible guesswork as to the relation of home environment to the health and intelligence of the child. I shall not be surprised to find, when further data are available, that the nation has for years been putting its money on "Environment" when "Heredity" wins in a canter. To say this is not to discourage all attempts to better defective sight in the schools or to check the intensification of myopia. But it would be foolish-in face of our increasing degeneracy-to neglect the possibility that only a complete change of our methods for social improvement can in the long run hinder the spread of defects. Better qualities, such as keen and strong vision, are no longer an absolute requisite for survival, and defectiveness, instead of meeting the stern judgment of Nature, is by governmental and charitable agencies supported to multiply its kind. The curative art in its tenderness for the individual may be disastrous for the race, unless it realizes fully the relative biological importance of heredity and environment.

\section{APPENDIX B}

\section{CLEANLINESS AND VISION}

Through the courtesy of Dr F. E. Rock, School Medical Officer of the Edmonton Education Committee, I have received data connecting the age, acuity of vision, and cleanliness of body and clothing of 953 Edmonton children. Statistically the data are somewhat erratic as there has been an age selection in testing the eyesight and clearly home environment, if we are to measure that by cleanliness of body and clothing, also produces an age selection. Dr Rock, as many another medical officer, not unnaturally, takes this cleanliness as the only measure available of home environment. Remembering what children are and will do, I must submit that it can never replace actually study of the homes and the parents. Taking it, however, as a measure of home environment, Dr Alice Lee provides me with the following correlations:

Age and acuity of vision - $\cdot 037$

(i.e. the vision is slightly worse for the elder children).

Age and home environment $+\cdot 029$

(i.e. the cleanliness is slightly better with the elder children).

Acuity of vision and home environment $+\cdot 072$. 
Hence the relation between goodness of vision and home environment for a constant age $=073$, or, the relationship between home environment, as measured by cleanliness of body and clothing, and goodness of vision is just about one-seventh of the intensity of the relationship between goodness of vision in parent and child. Nor are we sure that the home environment is the source of this small correlation; for not only do the statistics indicate a marked selection of the ages and the homes, but degeneracy in the parents, which is usually characterised by defective vision among other factors, may be the source of the want of cleanliness; and the association of this with bad vision be thus only a secondary hereditary effect. Until we know far better than we do at present the closeness of correlation between various physical degeneracies and the relation of these in the parent to the home environment, it seems hardly possible to determine whether these small correlations are really the expression of nurture, or only a secondary effect of nature. What is certain is that they are practically negligible compared with the direct effect of nature.

K. P. 


\title{
PART $I^{1}$
}

\section{SOME RECENT MISINTERPRETATIONS OF THE PROBLEM OF NURTURE AND NATURE}

\author{
By Karl Pearson, F.R.S.
}

One of the strange sequels to real human service is the not infrequent spectacle of a man of transcendent power being made a hero after his death by those who disregard the chief purpose of his life, often in fact by those who have not the faintest conception of what he aimed at, or indeed of what he actually achieved. Our intellectual leaders even to-day are treated as was Karl der Grosse, who within a few years of his death became the fabulous being who played with serpents, rather than the master, who had controlled and inspired men. There was this excuse in the case of Karl der Grosse-he left no writings of his own to indicate what his aims, his methods and his actions had been. The present day is the day of the printed word, when every man of mark leaves his message to be read by those who will, and yet-and possibly because of the superabundance of the written word-that message is not studied and we continue to fable about our heroes, as our forebears fabulated one thousand to two thousand years ago.

It would be an interesting psychological study in the birth of fable, if to-day we could first ask Francis Galton what he considered the main feature of his life-work, and we could then independently ascertain from a few of those who now celebrate his name what they suppose his chief aim and principal achievement to have been!

1 This lecture was delivered at the Galton Laboratory, March 17, I914. A portion of it amplified from the analytical side was issued in Biometrika, vol. $\mathrm{x}, \mathrm{pp}$. $18 \mathrm{I}-\mathrm{I} 87$. in a paper entitled: "On certain errors with regard to Multiple Correlation occasionally made by those who have not adequately studied the Subject." The correlation coefficients cited are chiefly due to Ethel M. Elderton and will be published with a detailed account as opportunity offers in the Eugenics Laboratory Memoir Series. 
I believe that from a knowledge of Galton's writings alone-apart from many intimate talks and much correspondence-I may safely assert that the very basis of his life-work was the conception that nature for man is more important than nurture, that this principle can be established quantitatively, and that only when it is fully realised will humanity be able to raise itself in the scale of mental and physical fitness. Did I not feel certain that this was his fundamental doctrine, and that this was the new pathway he hewed for human progress through the jungle of undemonstrated human opinion, I could not hold the post I do.

Galton's "transvaluation of all values" was not a rapid or easy one; he trod his own path as a solitary adventurer. He threw off some of the fetters of ancient opinion when he came in his journeyings of I845-6 through Egypt, the Soudan and Syria into contact with another faith, which he saw, or believed he saw, was more efficient than his own in the control of conduct among oriental races. $\mathrm{He}$ then grasped for the first time the relativity of religious belief, its geographical, racial and environmental associations. But it was not till the publication in 1859 of Charles Darwin's Origin of Species that Galton attained to a positive creed, and to that book he attributed his own actual freedom ${ }^{1}$. Henceforth he was a pioneer, if he led but a corps of guides and scouts.

But Galton differed essentially from Darwin, for his first idea was the application of the doctrine of evolution to the conscious uplifting of man by man himself. He desired above all things to accelerate by his own work the ascent of man, and the first problems which fascinated him were problems of human modifications due to environment, the possibility of the inheritance of acquired characters, the continuity of the germ plasm, the stirp theory, and generally all those problems which are fundamental in their bearing on the relative influence of nature and nurture. I well remember a conversation I had with him shortly before his death on this very subject. We were discussing the very bitter feeling that the papers by the staff of the Eugenics

1 "I always think of you in the same way as converts from barbarism think of the teacher who first relieved them from the intolerable burden of their superstition. I used to be wretched under the weight of the old fashioned 'arguments from design,' of which I felt, though I was unable to prove to myself, the worthlessness. Consequently the appearance of your Origin of Species formed a real crisis in my life; your book drove away the constraint of my old superstition, as if it had been a nightmare, and was the first to give me freedom of thought." Letter of Francis Galton to Charles Darwin, Dec. 24, 1869. 
Laboratory on the influence of environment had called forth, and he interjected: "I wish your critics would study the subject of twins and read my paper of I875." How many of our critics have even now read that paper? How many have really studied Galton's Hereditary Genius?

Here are the actual words ${ }^{1}$ he uses in the section of that work entitled "Nature and Nurture":

"When nature and nurture compete for supremacy on equal terms in the sense to be explained, the former proves the stronger. It is needless to insist that neither is self-sufficient; the highest natural endowments may be starved by defective nurture, while no carefulness of nurture can overcome the evil tendencies of an intrinsically bad physique, weak brain, or brutal disposition. Differences of nurture stamp unmistakable marks on the disposition of the soldier, clergyman, or scholar, but are wholly insufficient to efface the deeper marks of individual character" (p. I2).

How did Galton try to solve the relative strengths of "nature and nurture" - this "convenient jingle of words," as he terms it, which "separates under two distinct heads the innumerable elements of which personality is composed"? He noted that twins are of two kinds-those born physically and mentally alike, and those born as unlike as ordinary brothers and sisters. He proceeded to determine how far like twins were differentiated by unlike environments, and how far unlike twins were rendered like by their common nurture. $\mathrm{He}$ discovered that whatever the environment like twins remained alike and unlike twins remained unlike, even as they were born. Thus he sums up his History of Twins, as a Criterion of the Relative Powers of Nature and Nurture:

"There is no escape from the conclusion that nature prevails enormously over nurture when the differences of nurture do not exceed what is commonly to be found among persons of the same rank of society in the same country. My only fear is that my evidence seems to prove too much, and may be discredited on that account, as it seems contrary to all expectation that nurture should go for so little. But experience is often fallacious in ascribing great effects to trifling circumstances. Many a person has amused himself by throwing bits of stick into a tiny brook and watching their progress; how they are arrested, first by one chance obstacle, then by another; and again, how their onward course is facilitated by a combination of circumstances. He might ascribe much importance to each of these

1 Portions of this lecture have been used in Chapter I of my Life of Francis Galton, Cambridge University Press, I9I4. 
events, and think how largely the destiny of the stick has been governed by a series of trifling accidents. Nevertheless all the sticks succeed in passing down the current, and they travel, in the long run, at nearly the same rate. So it is with life, in respect to the several accidents which seem to have had a great effect upon our careers. The one element, which varies in different individuals, but is constant for each of them is the natural tendency; it corresponds to the current in the stream, and inevitably asserts itself." (Journal Anthropological Institute, I875, p. 39I, \&c.)

Such work as the Galton Laboratory has done was to give quantitative definiteness to this conclusion of its founder.

It is to me one of the most astonishing illustrations of the worship of the fabulous hero-the worship of the man whom you carve out as idol to appear what your fancy desires him to have been, regardless of what he was-when we find Francis Galton honoured by men who suggest "that at present we should, as far as possible, avoid such phrases as the relative influence of heredity and environment ${ }^{1}$," or who deny that there is evidence to show that the mental characters are inherited like the physical. To such men we can only cry in amazement: What in the world do you suppose Francis Galton did teach? What contributions do you imagine he really made to scientific knowledge? What principles do you consider he actually deduced for human conduct from his discoveries? When one member of the Eugenics Education Society preaches "the decadence of the Galtonian or biometric study of heredity," when a second holds that it is still an open problem whether mental characters are mainly due to heredity or to training, and when the President of the Society wishes to avoid the fundamental necessity of determining before action can be taken the relative influence of nature and nurture, surely we may demand of them why they honour Galton at $\mathrm{all}^{2}$ ? Is it only because a heterogeneous conclave needs some well-known flag to follow, requires the shadow of some great name to sanction its proceedings, regardless of what the flag stands for, or what were the most cherished principles of the man chosen as its fabulous hero?

But I shall get warmer than is fitting, if I stay to discuss this

1 Major Leonard Darwin, The Eugenics Review, vol. v, p. I54.

2 Another recent or present member of the Eugenics Education Society who prates much of "our master, the late Sir Francis Galton" states that "the fact remains that he omitted to discuss factors of racial injury which are quite immeasurably more important than any which he considered at all." As Galton once said of similar utterances, they remind you of the slathering of the boa constrictor preparatory to his making a meal of you. 
matter further. I must turn to the main topic of my lecture to-night, and bring up-as Francis Galton would himself have wished-such vagaries of opinion as I have quoted against the wall of solid statistical fact.

We have three fundamental questions to answer:

(i) What do we as Galtonians and Biometricians understand by heredity, and how do we measure it?

(ii) What do we of the same school understand by environment?

(iii) What do members of this Laboratory mean when they assert that nature or heredity is far more important than nurture or environment?

First what do we mean by heredity?

There are to my mind two distinct factors involved under the idea of heredity, which may not unfitly be described as interspecial (or even interracial) heredity and intraspecial (or intraracial) heredity. If every possible human being in a given race were equally likely to be the product of every possible male and female within the race, we as biometricians should assert that there was no heredity in the race. Our measure of heredity is the measure of the extent to which a deviation from average or type within the race is inherited by the progeny. If it is not inherited then there would be no intraracial heredity. We are perfectly aware that this is not the sense given to the word heredity by some biologists, they would attribute to heredity the fact that a goat produces a goat-and not a sheep-even if the characters of individual goats had no relation to parental deviations from type. The difference in meaning is not a subject for dispute, but a question of definition, of a proper understanding of the use of terms in a particular context. For a Galtonian heredity-or better intraspecial heredity-is a measure within a definite group of the inheritance of such deviations from type as actually occur within the group.

Secondly what does the Biometric School understand by "environment"? Certainly their idea of it is not identical with the silly sort of notion by which certain biologists consider they can demonstrate that nurture is more important than nature. Without environment they state an organism could not survive at all, hence environment must be more important than heredity. We might cap such an argument by asserting that as supermen would produce supermen, and as no environment has yet produced a superman heredity must be more effective than environment! What the biometrician understands 
by environment is the actual range of environments in which he finds the organism subsisting, and he asks whether when environment is varied within this range the characters of the organism are changed to the same extent as they are by such variations as occur in the ancestry of existing members of the race. In other words he measures and compares variations in the individual produced by varying existing environment and by varying ancestry among possible existing types. The biometrician does not stay to discuss what would happen if you kept your human being under a pressure of fire atmospheres or at a temperature of $100^{\circ} \mathrm{Fahr}$. The biometrician contents himself with a practical problem; he asks how changes which are withir the range of practical politics-the replacement of "back-to-back" houses by "through" houses, the abolition of cesspools, the diminution of overcrowding, the provision of better lighting or ventilation and so forth-would improve the child as compared with selecting parentage by sound health, efficient mentality and good habits. Such is the problem of environment and heredity that the biometrician has in mind, and such is the problem that he answers when he says that the influence of nature on the average is five to ten times as important as that of nurture. We assert that given the existing range of variation in possible parents and given the existing range of variation in possible environments, the association between variation in the offspring and variation in the parent is far more intense than the association between variation in the offspring and variation in the environment. We obtain this result by proving that the correlations in the two cases are of a wholly different order. In other words the relationship between parent and offspring is far closer to a causal bond than the relationship between environment and offspring.

Biometricians have, I hold, been perfectly consistent in what they have done; they have not used environment or nurture in any vague sense; they have taken the range of environment which occurs within practical experience, they have dealt with variations of nurture subject to municipal or state control; they have considered the time children spend in the school, at home, on the streets; they have dealt with occupations, wages and ages of parents; they have considered in short all the social, industrial and economic conditions of the environment of the child of which they could procure data, or which admitted of measurement and record, and they have shown that the variations in these factors of nurture are of relatively small importance compared with the results of variation in the physique, the mentality and the 
habits of parents. Surely before we can better the race effectually we must learn where our endeavours will have most effect. But because biometricians have ventured to consider what is after all the fundamental problem of Eugenics, nay indeed of all valid attempts to better social conditions, and because they have been forced to a conclusion which is opposed to much unfounded charitable and philanthropic opinion they have been calumniated as defenders of slums, as the servants of brewers and publicans, as the suborned agents of capitalists, and as modern Herods, whose object is to destroy infancy ${ }^{1}$.

If we turn from critics of this ill-balanced type of mind to those who read and think before they proclaim in the market-place, we still find almost as much obscurity in their criticism of what we have said and in their appreciation of the evidence on which it is based. What we complain of is that even our most friendly critics are liable to ascend the cathedra with a huge bag of phrases but rarely with a waistcoat-pocketful of established facts. I must stay to illustrate these points by quotations from one or two of our critics. Here are some remarks from a recent lecture by Professor J. Arthur Thomson:

"Character in its widest sense depends fundamentally on the innate organisation, but its expression depends largely on nurture. The adult mind is as much made as born.... Accepting Professor Pearson's valuable work, we are not, however, led to any depreciation of nurture, an art in which we are still in fact tyros.... There is little reason to suppose that we make anything like the most of our hereditary nature along the lines of psychical development. There are great fallow areas in the brain still to be cultivated. Instead of attaching too much importance to nurture, as Professor Pearson contended, we have not yet begun to attach enough."

I would draw the reader's attention to the passages I have italicised. Now these phrases are absolutely typical, for not a single measurable fact is produced to substantiate them. "The adult mind is as much made as born." What evidence is there for this? The direct evidence that it is not the fact produced by Galton is tacitly put on one side. Galton showed-and he has been confirmed by Thorndyke-that like twins remained absolutely alike under different environments, and that unlike twins did not become mentally or physically alike under the same environment.

1 A good illustration of this type of writing occurs in the recent utterances of a man of the market-place who throws overboard "all the deplorable and notorious nonsense published in the interest of obsolete statistical 'methods' or of class or political prejudice." 
If we are still "tyros in the art of nurture" is it not because we have never hitherto proceeded to measure the effect of various types of environment, but assumed that what made life easy for man must also be best for man? If mankind has remained a tyro after several thousand years experimenting, is it not rather idle for Professor Thomson to tell us that somehow or somewhere, he or somebody else is going to make more out of nurture? What evidence has he that there are "large fallow areas in the brain still to be cultivated"? Nature does not long preserve what is not used; she is nothing if not economical! Have those great fallow areas in the brain been lying idle since the date of our apelike ancestors, or only since neolithic times? What necessity of evolution called them into existence and why have they remained quiescent ever since? Which section of the brain do they lie in? How has Professor Thomson discovered that present day man is superman asleep, and what is the sort of nurturephosphorus or the pedagogue-which will rouse these fallow areas into activity? Such wordy dogmatism would be outbalanced by a single grain of the investigating statistical spirit of Francis Galton. Professor Thomson is a member of the Council of the Eugenics Education Society. Let us now turn to the words of its President.

Major Leonard Darwin writes as follows in the Journal of the Eugenics Education Society:

"It is impossible to compare heredity as a whole with environment as a whole as far as their effects are concerned; for no living being can exist for a moment without either of them ${ }^{1}$. Moreover, in order to compare two things so as to be able to use the words more or less in connection with such a comparison, we must have a common unit of measurement applicable to them both. But what is the unit by which both heredity and environment may be measured? I myself have no idea. May we not be discussing questions as illogical as enquiring what portion of the area of a rectangle is due to its width and what to its length? Is it ever wise to use words in scientific literature without endeavouring to attach a definite meaning to them ${ }^{2}$ ?"

1 There would in our sense be no heredity if the average child born to noteworthy parents was equal to the average child of the whole community. Yet it is perfectly easy to understand how living beings could exist under such a law of reproduction. Major Darwin seems to be confusing two things, interspecial and intraspecial heredity, the fact that a man is born true to his species, and the fact that he resembles his immediate ancestry. It is the latter fact only which concerns us when we compare heredity and environment, i.e. how far variation of immediate ancestry affects the individual's physical or mental characters. But without such heredity individuals might quite well exist.

: The Eugenics Review, vol. v, P. I52. The italics are mine. 
It is hard to conceive a paragraph of the same length more full of evidence of complete ignorance of the methods used in modern science for comparing correlated variates! Yet it goes out as the opinion of the President of a Society which is endeavouring to spread the scientific doctrines of Eugenics among the people! Major Darwin begins by stating that it is needful to have a common unit of measurement in order to compare two variates. To begin with we are not comparing two things, but we are comparing the influence of two things on a third, i.e. the intensity of a certain environmental influence and the intensity of a certain somatic character in the parent, say, on the intensity of the somatic character in the offspring. Yet Major Darwin tells us we cannot do this because we cannot measure these things in the same unit!-How suavely yet forcibly Sir Francis Galton himself would have ridiculed such ignorance in high places as is passed by the Editor of this Eugenics Journal!-We can see him now telling us how the intensity of each character could be measured by its grade, and how the problem turned on whether the same change in grade in the environment and in the parental somatic character produced greater or less change in the grade of the filial somatic character. When we inquire whether inter-racially stature is more closely related to cephalic index or to eye colour, are we to be met by the statement that these characters cannot be compared because they cannot be measured in a "common unit," and are we then to be told that it is not "wise to use words in scientific literature without endeavouring to attach a definite meaning to them?" Every trained statistician knows that each character is measured in the unit of its own variability-in what he terms its standard-deviation ${ }^{1}$, and that this standard-deviation provides him with a measure of the frequency of each value of the variate in question. It seems to me that the only correct sentence in this paragraph, is the author's statement that he himself has no idea what unit is "common" to heredity and environment.

But our author continues:

"Take any quality, and we find that the human beings composing any community differ more or less considerably as regards that quality. Now we can measure the correlation between the differences shown in this quality and the differences of environment to which the members of the community in question had previously been exposed ${ }^{2}$. This is

1 Of course he may or does need other constants to help in the description of the frequency.

loc. cit. p. I 53. 
one correlation. Then we can also measure the correlation coefficient between, say, father and son, as regards the quality in question. Here is a second correlation; and if we are told that the relative influence of environment and heredity is measured by the ratio between these two correlation coefficients, we certainly do thus get a clear conception of what is meant 1."

But has the writer really obtained a clear conception of what such coefficients of correlation mean, when in the next paragraph he continues:

"Imagine an ideal republic, in some respects similar to that designed by Plato, where not only were all the children removed from their parents, but where they were all treated exactly alike. In these circlumstances none of the differences between the adults could have anything to do with the differences of environments, and all must be due to some differences in inherent factors. In fact the environment correlation coefficient would be nil, whilst the hereditary correlation coefficient might be high ${ }^{2} . "$

Could any better evidence be adduced that the President of the Eugenics Education Society did not know what a coefficient of correlation meant at that date? The coefficient of correlation for the environment might be anything from - I to $+I$; the only obvious fact would be that you could not find its value, except in the form $\mathrm{o} / \mathrm{o}$, from an environment, which entirely precluded any occurrence of variation. How again Sir Francis would have smiled at the notion that the coefficient of correlation for a constant environment must be nil. Why should we follow such advice as that given by the President of the Society to avoid as far as possible "such phrases as the relative influence of heredity and environment," when on his own showing he does not in the least appreciate the methods by which this relative influence is measured?

Then Major Darwin continues:

"Surely what we want to know is how we can do most goodwhether by attending to reforms intended to affect human surroundings, or to reforms intended to influence mankind through the agency of heredity. But does this ratio [that of the environmental and hereditary correlation] give us any sure indication of the relative amount of attention which should be paid to these two methods of procedure?"

2 This seems to contradict the writer's previous assertion that two things are incomparable, if they have not a "common unit"!

2 I wrote at once to Major Darwin pointing out the error of such a statement and he withdrew it in the next number of his journal. But the harm done by an article of this kind cannot be reversed by correcting a single misstatement out of many. 
Our only reply can be that these correlations certainly do, and that as long as the President of the Eugenics Education Society fails to grasp their meaning, he is doing grave harm to the science of eugenics, and to the studies which Francis Galton had at heart.

One of the chief achievements of Francis Galton was his introduction of the conception of correlation to measure the relative intensity of those very factors of social progress, which the President of the Eugenics Education Society holds to be beyond comparison. Correlation measures for us the extent to which one variate is determined by a second; when correlation is high then we approach causation. When we say that the correlation of the character of the offspring with ancestral characters is ten times as intense as it is with environmental factors, then we mean that the degree of dependence of the child on the characters of its parentage is ten times as intense as its degree of dependence on the character of its home or uprearing.

Now if the reader will examine the accompanying tables which were published in a lecture of $19 \mathrm{IO}^{1}$ he will be at once struck by the wholly different order of the correlations due to Nature and those due to Nurture; we have an average Nurture correlation of about $\cdot 03$ as against a Nature correlation in the closest relationships of about $\cdot 50$. The number of these correlations have been very largely extended since that date and the diagram on p. 42 shows the distribution of frequency for a long series of Nurture and Nature values. It will be seen at once that the two frequency distributions have no common range. There is no real comparison possible between them, and whereas ancestry always draws the offspring in its own direction, a good environment may actually be associated with inferior physique or mentality in the child.

At this point, however, fresh criticisms of our work have been advanced, also by members of the same Eugenics Education Society. We admit, they say, that the environmental correlations may be of the order $\cdot 03$ or $\cdot 05$ and the inheritance correlations of the order $\cdot 50$. But this is the correlation of one character with environment. You ought to take ten or twenty, and then you will have multiplied up environment to be more effective than heredity for $\cdot 03 \times 20=\cdot 60$. In the first place we may suggest that it would be just as reasonable, if the argument were a valid one to multiply up the favourable hereditary characters, to take weight, height, muscular activity,

1 Nature and Nurture, The Problem of the Future, Eugenics Laboratory Lecture Series, No. VI, Cambridge University Press. 


\section{TABLE I. Strength of Nature.}

A. Parental Resemblances.

(i) Physical characters.

\section{Pair}

Father and son

n $\cdots$

Father and däughter

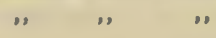

,, ,

Mother and son"

,,$\quad 0$

, , ,

Mother and daughter

$\begin{array}{lll}\text {, } & \text {, } \\ \text {, } & \text {, }\end{array}$

Parent and offspring

$\begin{array}{lll}\text {, } & \text {, } \\ n & n & n \\ n & n & n\end{array}$

Father and son

" " ,

Organ
Stature
Span
Forearm
Eye colour
Stature
Span
Forearm
Eye colour
Stature
Span
Forearm
Eye colour
Stature
Span
Forearm
Eye colour

(ii) Pathological characters.

Pulmonary tuberculosis (Pearson)

Insanity (Heron)"

Deaf-mutism (Schuster)

(Goring)

Corneal refraction (Barrington)

(iii) Mental characters.

Ability (Oxford Class Lists, Schuster)

Intelligence (Family Records, Pearson)

Mean Parental Correlation
Correlation

5 I

.45

.42

.55

5 I

45

42

.44

$\cdot 49$

.46

4 I

$\cdot 48$

.5 I

$-45$

42

.5 I
40 to $\cdot 60$

43 to 62

.53

.47

.54

.60

B. Fraternal Resemblances.

(i) Physical characters.

Brother and brother

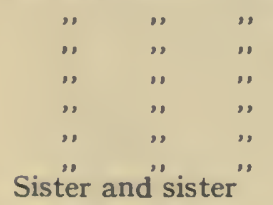

\begin{tabular}{|c|c|c|}
\hline " & $\because$ & " \\
\hline 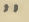 & 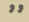 & " \\
\hline$"$ & $\because$ & " \\
\hline ", & & ," \\
\hline , & $\because$ & , \\
\hline , & 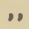 & , \\
\hline
\end{tabular}

Stature

Span

Forearm

Eye colour

Cephalic index

Hair colour

General health

Stature

Span

Forearm

Eye colour

Cephalic index

Hair colour

General health 
TABLE I (continued)

Pair

Brother and sister

$\begin{array}{lll}\text {, } & , & , \\ , & , & , \\ , & , & , \\ , & ,\end{array}$

Pairs of siblings

" , ,

, , ,

Brother and brother

Sister and sister

Brother and sister

Pairs of siblings

" " "
Organ

Stature

Span

Forearm

Eye colour

Cephalic index

Hair colour

General health

Correlation

$\cdot 55$

.53

44

$\cdot 46$

43

.56

.62

(ii) Pathological characters.

Phthisis (Pearson) $\quad 48$

Insanity (Heron) 5 I

Deaf-mutism (Schuster) 73

(iii) Mental characters.

Ability $\quad .52$

", - 45

Temper $\quad 49$

Handwriting $\quad .51$

Mean Fraternal Correlation $\quad 52$

Mean "Nature" value $5 \mathrm{I}$

\section{TABLE II. Strength of Nurture.}

Pair of characters dealt with

Correlation

Keenness of vision and home environment as measured by cleanliness

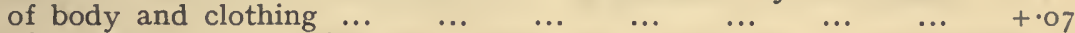

$\begin{array}{lllllllll}\text { Eye disease and overcrowding } & \ldots & \ldots & \ldots & \ldots & \ldots & \ldots & +\cdot 05\end{array}$

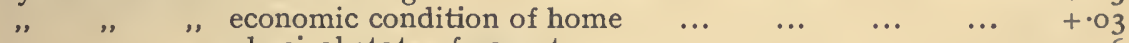

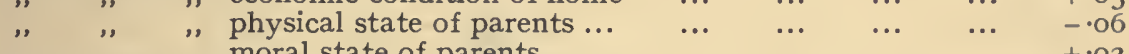

M"yopia" and age moral state of parents $\begin{array}{lllllll}\ldots & \ldots & \ldots & \ldots & \ldots & +\cdot 02\end{array}$

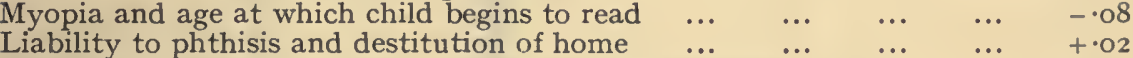

Keenness of vision and overcrowding (no. of persons per room) $\quad \begin{array}{llll}\cdots & \cdots & -\cdot 10\end{array}$

Myopia and overcrowding (no. of persons per room) $\quad \begin{array}{lllll}\text {... } & \ldots & \ldots & & -.07\end{array}$

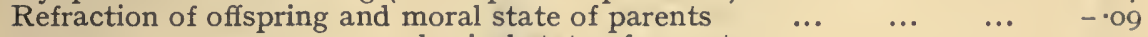

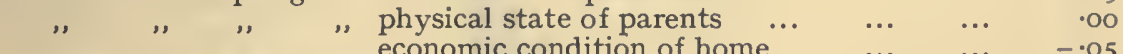

Keenness of "vision" and ", economic condition of home $\quad \ldots \quad$... $\quad$-.05

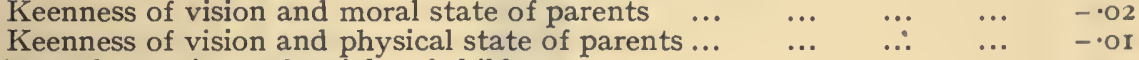

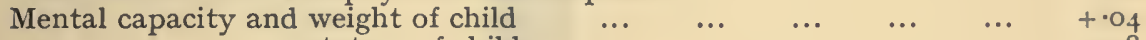

\begin{tabular}{|c|c|c|c|c|c|c|c|c|}
\hline & & & & & & & & \\
\hline " & ", & $"$ & stature of child & $\cdots$ & $\cdots$ & $\cdots$ & ... & $+\cdot .08$ \\
\hline$"$ & ", & ", & condition of teeth. & $\ldots$ & $\ldots$ & ... & ... & $+\cdot 09$ \\
\hline ", & $"$, & ", & condition of clothing (boys & )... & ‥ & $\cdots$ & ... & $+\cdot 04$ \\
\hline$"$ & ", & ," & condition of clothing (girls) & $\ldots$ & $\ldots$ & $\ldots$ & $\ldots$ & $+\cdot 24$ \\
\hline$"$ & $"$ & ", & state of nutrition (boys) & $\ldots$ & ... & ... & ... & $+\cdot 01$ \\
\hline ", & ", & ", & state of nutrition (girls) & $\cdots$ & ... & ... & ... & $+\cdot 08$ \\
\hline ," & ", & ", & cleanliness (boys) & $\ldots$ & $\cdots$ & $\cdots$ & ... & $+\cdot 1_{4}$ \\
\hline ", & ", & ", & cleanliness (girls) & $\ldots$ & ... & ... & ... & 07 \\
\hline ", & ", & ", & state of glands in children & ... & $\cdots$ & ... & ... & $+\cdot 08$ \\
\hline " & ", & ", & state of tonsils (boys) & ... & $\cdots$ & ... & ... & OOI \\
\hline ", & ", & ", & state of tonsils (girls) & ... & $\ldots$ & $\ldots$ & $\cdots$ & $\because$ I I \\
\hline
\end{tabular}




\section{TABLE II (continued)}

Pair of characters dealt with

Correlation

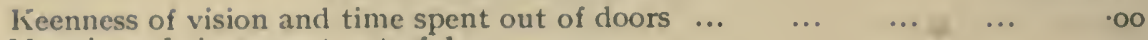

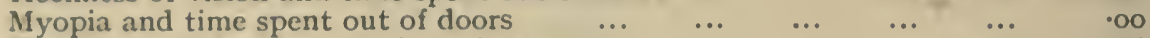

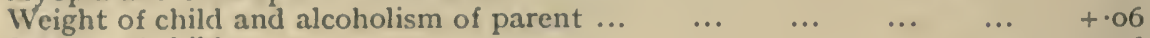

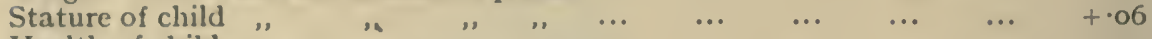

Health of child ", $\quad " \quad$ " $\quad$ " $\quad \begin{array}{llllllll} & \ldots & \ldots & \ldots & \ldots & \ldots & - & -05\end{array}$

Intelligence of child and alcoholism of father $\quad \begin{array}{llllll}\ldots & \ldots & \ldots & \ldots & -.06\end{array}$

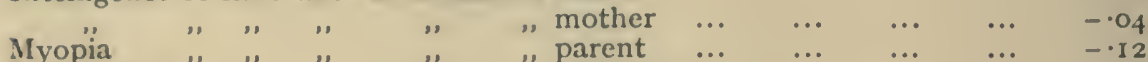

Eye disease "

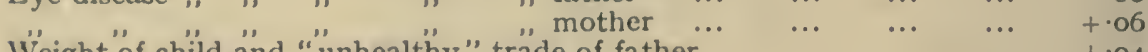

Weight of child and "unhealthy" trade of father $\quad \ldots \quad \ldots, \quad \ldots \quad+.04$

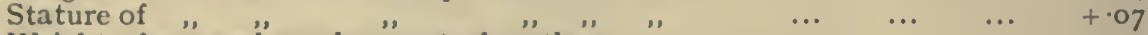

Weight of son and employment of mother $\quad \ldots \quad$.. $\quad \ldots \quad \ldots \quad$ +.II

Weight of daughter and employment of mother $\ldots \quad \ldots \quad \ldots \quad \ldots \quad \ldots \quad+\cdot 07$

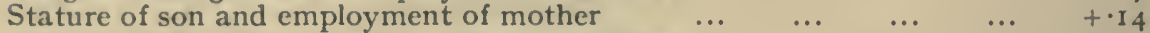

Stature of daughter and employment of mother $\ldots \quad \ldots \quad \ldots \quad \ldots \quad \ldots \quad+$. II

Intelligence of son and employment of mother $\quad \begin{array}{llllll}\ldots & \ldots & \ldots & \ldots & -\cdot 16\end{array}$

Intelligence of daughter and employment of mother $\quad \ldots \quad \ldots \quad \ldots \quad+\cdot{ }^{\prime}$ I 2

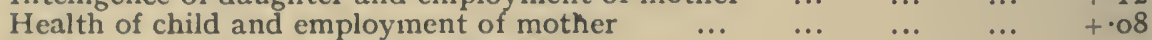

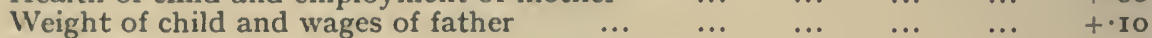

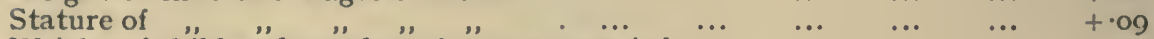

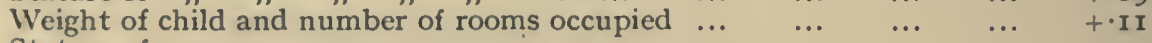

Stature of " " ",$\quad$ "

Mean Nurture Value $\quad \ldots \quad \ldots \quad+{ }^{\circ} 03$

A negative sign in the above table indicates that an unfavourable parental or environmental condition appears on the basis of the data available to show improved welfare in the child.

Comparative Values of Nature and Nurture Correlation Coefficients.

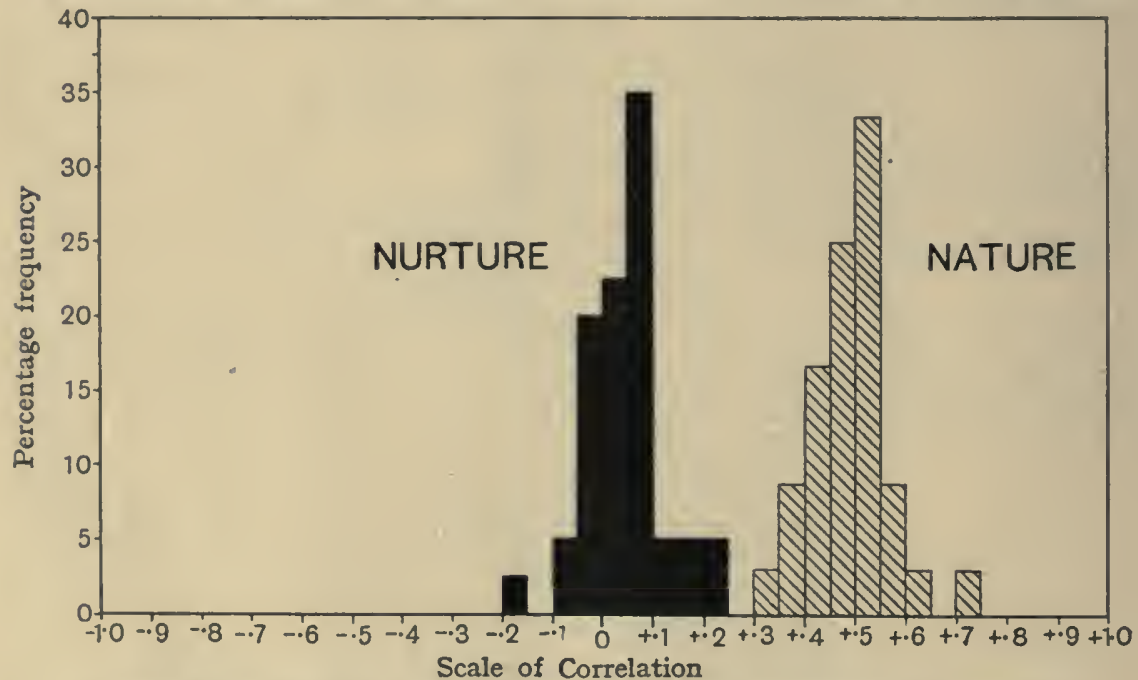

Values available when diagram was drawn and tabled without selection to sub-ranges of 05 . 
health, intelligence, caution, and many other desirable factors, and these not only in one parent but in brothers, sisters, aunts, uncles and grandparents and treat the cross-correlation of these with the character under discussion. But although every improvement in stock would reflect itself in improvement in offspring, correlations cannot be added together-any more than forces by simple arithmetical addition. You do not combine two hereditary correlations any more than two environmental correlations by mere addition. You must proceed by a combination process which is of course familiar enough to the trained statistician.

Yet here is a statement which the Editor of the Eugenics Review admits without contradiction to its pages $^{1}$ :

"The point that we wish to make is this. In the face of so much ignorance concerning, not only hèredity itself, but also its complement, the influence of environment, how can any one be justified in making sweeping generalisations with reference to these subjects?

Such generalisations, however, are made. It is said that we have a definite proof that inheritance is of far greater strength than environment. This argument takes the following shape. The correlations between parent and offspring for a number of features have been calculated, and the mean is found to be somewhere about 5 . Correlations between individuals and various aspects of their environment have also been worked out-as, for instance, mental ability and conditions of clothing, or between myopia and the age of learning to $\operatorname{read}^{2}$ - and the mean value is found to be about $\cdot 03$. It is then said that the mean 'nature value' is at least five to ten times as great as the mean 'nurture value,' and upon this is founded the generalisation that 'nature' is of far greater importance than 'nurture's. It may be questioned, however, whether such a comparison does not involve a serious mistake. For if we consider the two mean values that are compared, we find that, whereas the 'mean nature value' is the mean value of a number of observations, all of which provide a full measure of the strength of heredity, the 'mean nurture value' is the mean value of a number of observations, each of which measures only the strength of some one isolated aspect of environment. It would appear then that the full strength of inheritance has been compared, not with the full strength of environment, but with the average of a number of small

1 Vol. v, p. 219, in an article by A. M. Carr-Saunders.

2 As the writer phrases this correlation, it is very liable to be misinterpreted. What the Galton Laboratory did was to show that myopia was very markedly inherited, and that the theory that it was largely due to school environment was incorrect, because children who began to read late, i.e. went late to school, were not less myopic than those who went early.

Karl Pearson, Nature and Nuriure, Eugenics Laboratory, Lectures VI, p. 25. 
isolated aspects of the latter. As a matter of fact it is quite beyond our power at present to sum up the full effect of environment upon the individual and compare it with the full effect of heredity. We are, therefore, justified in saying that we neither know in particular cases how far the environment can produce any effect, nor can we make any definite statement as to the comparative strength of 'nature' and 'nurture."

Now this is the doctrine passed by the Editors of the Eugenics Review, a society, which masquerades under the name of Francis Galton ${ }^{1}$, and it is passed, because the editorial committee of that society does not grasp the meaning of multiple correlation! In the first place, of course, a single correlation coefficient does not provide a full measure of the strength of heredity. In the table cited the coefficients are those for one parent or for one brother or sister. Each relative-and those for independent stocks are either non-correlated or inter-correlated very slightly-provides such a coefficient, and further each character in such relatives may be correlated with the character under discussion in the person in question. In the next place the environment factors do not consist of "some one isolated aspect of environment." All these factors or aspects are closely interlinked, and this was a fact well-known to the workers in the Galton Laboratory. The real interpretation of such a difference as $\cdot 50$ and .03 in the average values of single coefficients can only be appreciated by those who are conversant with the theory of multiple correlation, and it is quite clear that those who profess to guide the public in this very difficult problem-which is essentially a scientific problem-lack any adequate knowledge of the sole instrument by which any legitimate conclusion can be drawn.

The writer quoted appears to be wholly ignorant of the nature of multiple correlation in the first place and in the second entirely to overlook the very high correlations which exist between environmental factors. Bad wages, bad habits, bad housing, uncleanliness, insanitary surroundings, crowded rooms, danger of infection, \&c., \&c. are all closely associated together, and while the order of correlation between environmental and physical characters is low, that between individual environmental factors is in our experience very high. Thus the problem of heredity and environment is essentially the same as the problem of multiple correlation.

1 If there was one point on which Francis Galton felt strongly and wrote it was on this point of the relatively great intensity of "nature" as compared with "nurture." 
But does any one trained in statistics believe that you add correlation coefficients together to get their combined effect?

You might as well suggest that when you combine a force of ro lb. with a force of ro $\mathrm{lb}$. the resultant is $20 \mathrm{lb}$., whereas it might be $2 \mathrm{lb}$. or possibly zero. The whole relationship depends on the angle between the forces. In the same way the value of the coefficient of multiple correlation depends on the correlations between the combined factors.

It is absolutely needful to impress this on the reader, and I will illustrate it for a special case. Let the problem be: How far does professional occupation, and prosperity influence the size of the family?

I take for the London districts ${ }^{1}$ the number of births per roo wives from $15-54$ in a district. I take the number of professional men per Iooo occupied males and the number of female domestic servants per Ioo females. We have:

Correlation of births and professional men $=-\cdot 78$;

and domestic servants $=-\cdot 8 \mathrm{o}$.

Now suppose we wanted to find the total effect of professional occupation and middle class prosperity as measured by the prevalence of domestic servants on the birthrate. If you were to add -.78 to $-\cdot 80$ you would get $-I \cdot 58$, which is senseless, for correlation cannot be greater than the perfect value unity! Actually the multiple correlation coefficient is $-\cdot 82$, only .02 more than the value as found for domestic servants alone and this result is as wholly reasonable as the additive result was wholly fallacious. For to provide a measure of the professional men in a district is almost equivalent to providing a measure of the domestic servants in the same district. The correlation between these two measures is in fact $+\cdot 85$. A knowledge of the two factors does not give double information, and enable us to determine double as accurately the birthrate; it only raises the correlation from -.80 to -.82 .

Let us take a second illustration of this same most important principle. Suppose we desire to predict the probable character of an individual from (i) his two parents or from (ii) a large number of his brothers and sisters. In the first case and in the second the correlation between the individual and one only of his relatives is about the same,

1 See Heron, On the Relation of Fertility in Man to Social Status, \&c., Cambridge University Press, Drapers' Company Research Memoirs. 
namely 50 . But there is an essential difference between the two cases; pairs of brothers or sisters have a relatively high correlation with each other, namely 50 , but parents have a low correlation with each other, on the average in the middle classes, perhaps, $\cdot 15$, due to assortative mating; in the lower classes this sinks almost to zero. The following table gives the results:

\section{TABLE III.}

Showing the Effect of Intercorrelations between Relatives, when a Judgment has to be formed of the Character in an Individual $(A)$ from a knowledge of it in his Relatives.

Multiple Correlation Coefficients

\begin{tabular}{|c|c|c|c|c|}
\hline$A$ and & $\begin{array}{l}\text { No assortative } \\
\text { mating }\end{array}$ & $\begin{array}{c}\text { Assortative } \\
\text { mating }\end{array}$ & $A$ and & \\
\hline $\left.\begin{array}{l}\text { Two parents } \\
\text { Two parents } \\
\text { and four } \\
\text { grandparents }\end{array}\right\}$ & $\cdot 707$ & $\cdot 659$ & 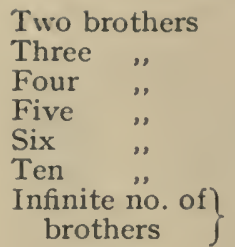 & $\begin{array}{l}.577 \\
.612 \\
.633 \\
.646 \\
.655 \\
.674 \\
.707\end{array}$ \\
\hline
\end{tabular}

Thus we see that unless there be assortative mating, we do not better matters by introducing for the purposes of prediction the four grandparents. And even with assortative mating two parents are worth more than six brothers or sisters. Two parents who have not selected their likes would form as good a basis for prediction as an infinity of brethren, were such indeed available. Now the correlation between brethren is only $\cdot 50$, and that between environmental factors is often higher, thus this illustration will indicate how very little additional intensity of correlation is gained by combining intercorrelated factors. We do not add the correlations due to separate factors as Mr Carr-Saunders' paper appears to suggest. If the factors are absolutely independent, as when persons marry without assortative mating, then the multiple correlation coefficient is the square root of the sum of the squares of the correlations combined.

Thus if we took roo independent environmental factors with a strength of about $\cdot 05$, the resulting combined or multiple correlation 
would only be $\cdot 50$, the value of the correlation of an individual with a single parent.

If we suppose a system in which the environmental correlations are roughly of the same order, and the inter-environmental correlations approximately of value $\epsilon$, we shall be able to deduce approximately the multiple correlation of the individual with $n$ factors of environment by multiplying the mean environmental correlation by the quantity $\sqrt{\frac{n}{I+\epsilon(n-I)}}$. The following table provides the value of this expression for values of $n$ and of the mean inter-environmental correlation $\epsilon$.

TABLE IV.

Table of multipliers for estimating approximately the effect of combining $n$ environmental factors.

Number of Environmental Factors

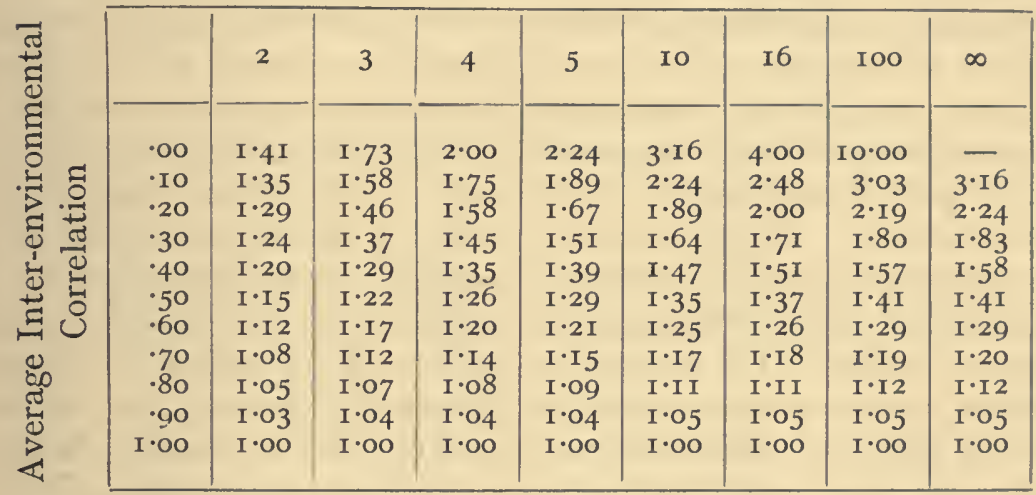

Now this table brings out some exceedingly interesting points. In the first place if the inter-environmental correlations were as low as $\cdot 30$, we should not double the multiple correlation of the individual and his environment by taking into account an infinity of environmental factors. If the inter-environmental correlations were as high as 60 , we should only add about $30 \%$ to the mean value of the correlations of the individual's character with the environmental factors. It will be seen how soon we reach a limit to the sensible increase of association obtained by combining numerous environmental factors even if these be only moderately correlated together.

See Biometrika, vol. x, p. $18 \mathrm{r}$. 
For example suppose we took roo environmental factors-rather more I fancy than we could ever hope within a reasonable time to modify by social or political effort-and considered their intercorrelations to be of order 40. Then we should have to multiply by the factor $1 \cdot 57$. Thus with an average environmental correlation of $\cdot 05$, the result would not be $\sqrt{100} \times \cdot 05$, i.e. the -50 of independent environmental factors, still less the unintelligible $100 \times \cdot 05$ of Mr Carr-Saunders' notion, but only $1.57 \times \cdot 05=.078$, or not a sixth part of the intensity of the hereditary influence of a single parent!

I propose that we should now turn to a more detailed study of environmental correlations in order to measure the applicability of the above results. Five years ago in the lecture on Nature and Nurture, the Problem of the Future, I put before my audience the Tables I and II just reproduced (p. 40). The average value of the Nature factor was $5 \mathrm{I}$ and of the Nurture factor 03 . I never anticipated that any one would be so misguided as to crudely multiply .03 by $\mathrm{I} 7$ and then compare the result with the hereditary correlation for a single character between a single pair of relatives. But I have learnt much in these five years, and not the least important element of my knowledge is the confirmation of my opinion that the great battle-cries of social parties will in the present century turn on this problem of Nature versus Nurture ${ }^{1}$. In the consciousness of this development the Galton Laboratory has devoted much of its energies during this period to the accumulation of data bearing on the influence of environment on child welfare. Owing to the unremitting labours of my colleague Ethel M. Elderton, we now know vastly more than we did five years ago. Where we then knew one environmental correlation we now know a dozen; further we have learnt the necessity for the classification of these environmental factors, not only because certain classes are capable of direct municipal control and others are not, but because certain classes must be met by educative rather than by legislative action if they present features which call for remedy ${ }^{2}$. If we term "environmental,"

1 Since this lecture was delivered the present war has come to test on a gigantic scale how far free political institutions are compatible with the national organisation requisite for national survival. However the war may ultimately end it cannot fail to emphasise the movement towards national organisation as a necessity for existence. This national organisation cannot stop short at organising the existing, it must face the wider problem of how to obtain the highest type of citizen as material for organisation.

It is characteristic of this period of change that greater stress is being laid on educative remedies, especially on the instruction of parents. This is in accord with the result reached by the Galton Laboratory that parental habit is far more influential 
all the influences that follow the birth of an individual-climate, housing, food, parental conduct,- - and do not distinguish between these various classes, we may be able to show that environmental are less influential than hereditary forces, but we shall not discover which categories of environmental forces are most worth dealing with out of the wide field provided by nurture. We shall distinguish first accordingly between the physical environment-housing, sanitation and ventilation-which within certain limits can be modified by legislation or municipal regulations-and parental environmentcleanliness, wage-earning power, feeding, parental habits and parental health. But even this classification is not clear cut. For example relative to other factors we find ventilation an element of some importance in child nurture. But there are two phases of ventilation-the one an absence of the means of ventilation is a feature of true physical environment, but the other phase the neglect of existing means of ventilation is a feature of parental environment that is of parental habit. It may thus be quite as much a nature as a nurture factor. As a matter of fact the second phase of ventilation is more highly correlated than the first with health in the child, and the reader will find this result almost universal: whenever a nurture factor can be interpreted as possibly an indirect nature factor then it is likely to be more influential.

Take the case of suitable feeding again, this may depend upon father's wage, and that on his physique, or it may depend on the mother's efficiency as a housekeeper, which in turn is closely related to her habits and health. Or again it may be the outcome of municipal arrangements as in the provision and inspection of milk supply; further geographical conditions may produce effect when we contrast urban with rural districts, or the great seaports ${ }^{1}$ with manufacturing towns.

than physical environment. But just as popular opinion has overlooked the necessity for estimating the relative intensity of Nature and Nurture in past measures of social reform so it appears to escape our present pioneers of educative methods that a fundamental a priori problem is to determine how far parental habits in the mass are the product of tradition or of inheritance-the heredity of an inert nature: indeed there is further some evidence that the tendency to maintain traditions is itself largely a racial character. We not only observe that individuals brought up under the same environment, physical and educational, have wholly different standards of order and cleanliness, but a very small experience even of European travel shows that order and cleanliness are racial characters, which are as conspicuous in certain European lands as the predominating negligence and filth in others.

1 The relation of infantile diseases to food supply deserves careful study. The prevalence of diphtheria in seaports may be connected with this subject. 
In these aspects feeding is associated with physical rather than parental environment. It will thus be evident that our division into categories can only be very general. Even such a physical feature as "housing" may be really a result of nature. An alcoholic father may mean irregular wage and this enforces low rent and so bad housing on the children. We have therefore in some way to get rid of parental habits and parental health from the physical environment correlations before we can say, this is the measure of pure nurture on child welfare. We achieve this by correcting for these nature factors, we take the partial correlation of the physical environmental factor with the child's health or other welfare character for constant parental habits and health. We must allow for the fact that the physically and mentally inferior parents tend to occupy the cheaper houses. It is impossible to attribute to the house what is really due to physical and mental wreckage drifting where there is least to pay. It is largely this fact, not the physical state of the home which is reflected in the nurture of the children. With the assistance of Miss Elderton I have endeavoured to classify "environmental factors" as follows:

(i) Physical Factors, as in housing and sanitation.

(ii) Parental Factors.

(a) Direct Parental Factors as in Habits, Cleanliness, Use of Ventilation, \&c.

(b) Indirect Parental Factors as in Wage, Occupation of Father, Employment of Mother, \&c.

Now I will ask you to look at the accompanying Table $\mathrm{V}$ for three manufacturing towns, Rochdale, Bradford and Blackburn. It does not cover any material previously deait with in this paper and is a fair sample of the environmental correlations we have reached. On the left-hand side of the table we give the crude correlation values; on the right-hand side we correct these correlations in part for health and habits of parents, so as to remove as far as possible the nature factor. But we have only been able to do this in part. Thus for Rochdale we could correct for habits of parents only; for Blackburn we could correct for health of parents only. In Bradford we have corrected for health of mother only. Thus it will be clear that the values reached are not true corrected values, but maximum values, the actual associations between welfare of child and pure environmental influences being still lower than those recorded in our "corrected" columns. Now the reader will observe that of the three main divisions Physical Environment, Indirect Parental Environment 


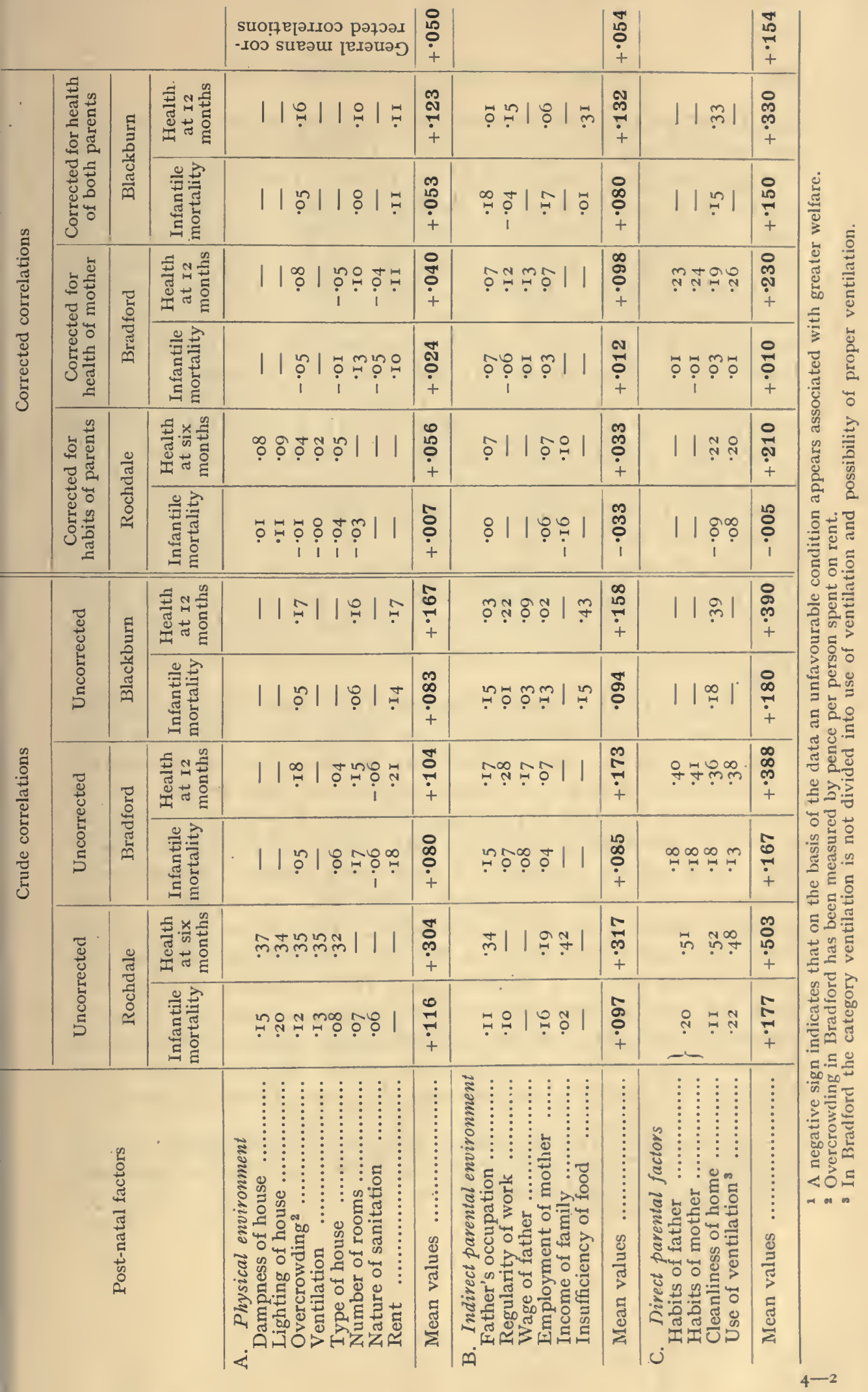


and Direct Parental Environment, only the correlation coefficients in the last case rise to any significance. The Physical Environment is of small importance compared to the Parental Environment, and we are really thrown back on the Health and Habits of Parents as the only really important factors in infantile mortality and the health of surviving children. We have shown elsewhere that general health is a markedly hereditary character". With "Habits" the case is slightly but not essentially different. There is evidence that the habits of the mother are not only very sensibly correlated with her health $(.52$ in Bradford), but that the father's habits are also associated with the mother's health ( 49 in Bradford). These matters will be discussed at length when our full data are published, but it is clear that the father of bad habits is far less frequently able to procure a wife of good health than a father of good habits, and that apart from the heredity of the orderly habit, the orderliness of the mother is sensibly a matter of health-itself an hereditary character. As far as the evidence of Rochdale, Bradford and Blackburn extends, we seem safe in asserting that the Physical Environment correlation will give a mean value below $\cdot 05$, and that probably if we could fully correct for health and habits of both parents the mean value would scarcely exceed .03 or $\cdot 04$.

In regard to the Indirect Parental Environment the correlations when corrected for parental habits and health are of much the same order. Only in the case of Blackburn do they reach in the matter of insufficiency of food (-3I) to any importance. But in this case we cannot correct for habits of parents, although we know that insufficiency of food is very sensibly correlated with father's health $\left(\cdot 40^{2}\right)$, father's wage $\left(\cdot 45^{2}\right)$ and his regularity of work $\left(\cdot 6 \mathrm{I}^{2}\right)$, indirect environmental factors of the parent, all closely associated, as experience from elsewhere shows, with the father's habits. Thus we are left with the Direct Parental Environment as the only sensible influence on the mortality and health of children up to twelve months of age. But when we look at such factors as cleanliness of house and use of ventilation, and note how the crude Rochdale values are reduced by correcting for habits of parents, the crude Blackburn values by correcting for health of parents and the crude Bradford values by

I See Biometrika, "On the Hereditary Character of General Health," vol. IX. pp. 320-329 and "Questions of the Day and of the Fray," No. VI, Eugenics and Public Health, Cambridge University Press.

2 Values for Blackburn. 
correcting for health of mother alone, we may well ask what would be left of the mean value -I54, if full corrections for both health and habits had been made. The present movement to educate parents is right in so far as it recognises that the essential factor in the environment of the young child is the direct parental rather than the direct physical environment. The parental health and the parental habits are everything. But again the educationalists like the environmentalists have overlooked the necessity for a preliminary inquiry in order to determine: (a) How far is health of parent an hereditary character? (b) How far are habits the outcome of health? and (c) How far are habits themselves-orderliness and inertness of mindthe result of inheritance? Just as the environmentalists have neglected the dominance of nature over nurture in child welfare, so there is danger that the far more reasonable movement of the educationalists will fail if they do not give due weight to the hereditary factor in dealing with both the health and habits of parents.

We have next to consider the interenvironmental correlations. Our chief illustration will be from Rochdale, the data for which are not only more complete but have up to the present been more fully worked out. We shall consider in order: $(a)$ the correlations between factors of physical environment, $(b)$ the correlations between factors of indirect parental environment and $(c)$ the correlation between the physical and indirect parental environments ${ }^{1}$.

\section{TABLE VI.}

Intercorrelations of Physical Environmental Factors. Rochdale.

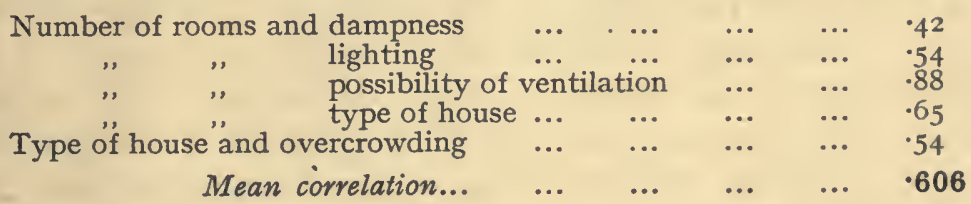

It will be seen at once that the intercorrelations of the Physical Environmental factors are of a totally different order to the correlations of those factors with infant welfare.

1 The exact measurement of the characters, the methods by which the correlations were determined, the size of the populations dealt with, and other features of the work will all be published at length later with the tables of data. They cannot be reproduced in a mere lecture. Thus "sanitation" covers cesspool, pan, and water closet; type of house, "back to back" and "through" houses; father's occupation skilled and unskilled, \&c., \&c. 
In the next table we find illustrations of the correlations between physical environment and indirect parental environment. I have in this table purposely left out the correlations of mother's employment with certain other factors for our experience has shown that its effect is of a mixed nature. It may arise from extreme poverty, i.e. be associated with low wage of father and thus with insufficiency of food, or in other cases, especially in the textile towns, the young mother almost invariably goes to work and this work is a source of increased family income and better food supply. The high correlation given above for emplovment of mother and income of family show that in Rochdale the work of the mother is a source of prosperity ${ }^{1}$.

\section{TABLE VII.}

\section{Intercorrelations of Indirect Parental Environmental Factors.} Rochdale and Blackburn.

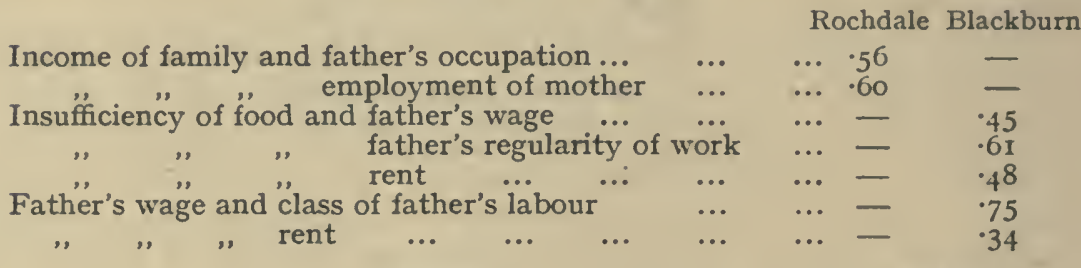

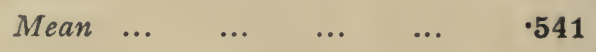

We next turn to the intercorrelation of physical and indirect parental factors in the following table (Table VIII).

It will be seen that these intercorrelations are brought below $\cdot 50$ owing to the last two values for overcrowding. I doubt very much whether overcrowding as measured by persons per room is to be considered as a fair measure of bad environment; it frequently denotes only numerous children in a possibly prosperous home. There are obviously mixed causes at work, largely depending on the age of both father and mother, when we consider the association of the wage of the former and the employment of the latter in relation to overcrowding.

1 In Blackburn the correlation of mother's employment with father's wage (not total income of family) is -27 , with insufficiency of food -.03 and with cleanliness of home -02. All these results in my opinion show the influence of mixed causes, poverty compelling to employment in some cases and the increase of prosperity following from employment in fairly prosperons families actually bettering the home conditions in other cases. 


\section{TABLE VIII.}

Intercorrelation of Physical and Parental Environmental Factors. Rochdale and Blackburn.

Indirect parental environmental factor and physical environmental factor

Insufficiency of food and number of rooms

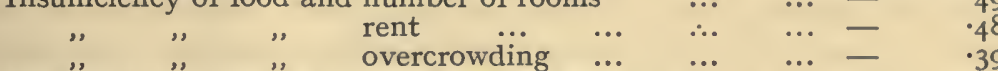

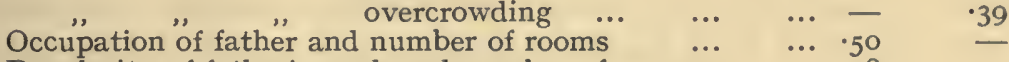

Regularity of father's work and number of rooms $\quad \ldots \cdot 4^{8}$

Father's occupation and overcrowding $\quad \ldots \quad \ldots . \quad \ldots \quad \cdot 45 \quad$ -

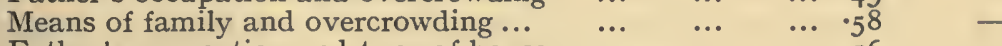

Father's occupation and type of house $\quad \ldots \quad$... $\quad \ldots{ }^{56} \quad$ -

Means of family and type of house ... $\quad \ldots \quad \ldots . \quad \ldots \quad \cdot 58$

Income of family and type of house $\quad \ldots . \quad \ldots . \quad \ldots .67$

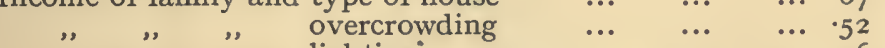

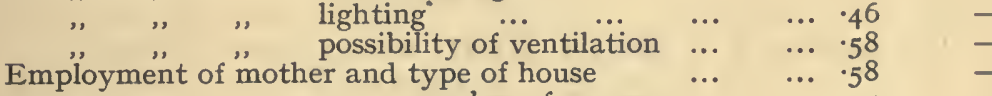

Employment of mother and type of house $\quad \ldots . \quad \ldots \quad \cdot 58$

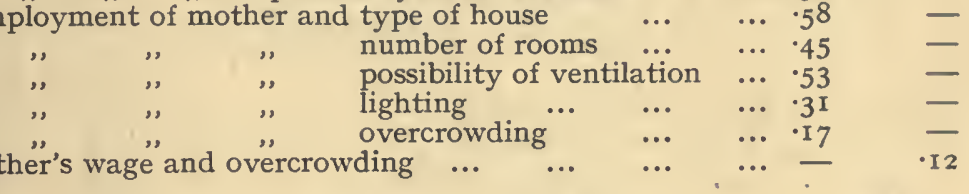

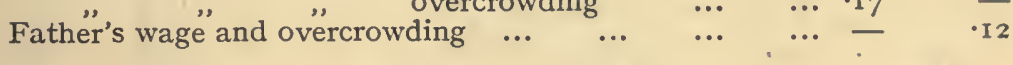

Mean correlation $\quad \ldots \quad$... $\quad \cdot 468$

We now turn to the Direct Parental Environmental Factors which form a very closely correlated group.

\section{TABLE IX.}

\section{Intercorrelations of Direct Parental Environmental Factors.} Rochdale and Bradford.

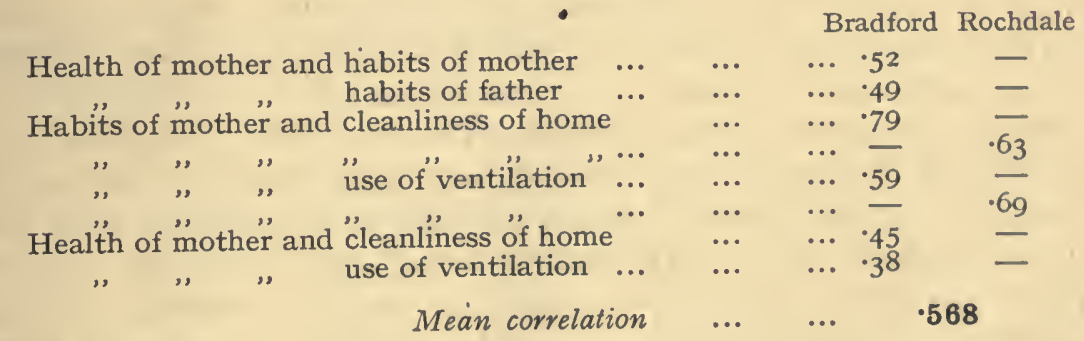

This the direct parental factors of environment, which we know in the case of health and suspect in the case of habits to be largely hereditary have an intercorrelation of the order $\cdot 6$. 
Now although it seems proper to exclude these probably hereditary factors from an examination of true environmental factors it is worth while to notice the extent to which the indirect parental and physical environmental factors depend on the direct parental factors. The fact is that parents of bad habits and poor health by a process of selection gravitate to the worse type of dwelling. When we remember that infant mortality and health of mother have a correlation of $\cdot 30$ in Blackburn, and delicacy of infant and health of mother a correlation of $4 \mathrm{I}$ in Bradford, while health of offspring and health of either parent have a correlation of about $\cdot 50$ in the professional classes, we realise how largely health is a matter of nature, not of nurture. In confirmation of this consider the following results:

\section{TABLE X. \\ Association of Health of Mother with Physical Factors. Bradford and Blackburn.}

Health of mother and overcrowding
"

* Measured for Bradford by pence per person spent on rent.

It would thus appear that the association of bad physical environment with mother's bad health is not a third as intense as the association of mother's health with that of her offspring. Even then it would be wrong to assert that the bad health of the mother flows from the environment. The unhealthy woman fails to find a healthy normal husband, she is less often employed and thus the family income being lower, there is more overcrowding, and the home is made in a cheaper and inferior type of house. The fact that in Blackburn the correlation between mother's health and insufficiency of food in the family is 47 and between father's health and insufficiency of food is 40 , indicates how greatly health in parents affects the economic condition of the family. It may be doubted whether physical environment would show any sensible relation to mother's health were the values corrected for income of family.

On the other hand as the next table will show the direct parental environmental factors summed up in habits of mother and cleanliness 
of home are closely associated with the factors of physical environment. The data in this table are for Rochdale and Blackburn:

TABLE XI.

Influence of Direct Parental Factors on Physical Environmental Factors Rochdale and Blackburn.

\begin{tabular}{|c|c|c|c|c|c|c|c|}
\hline \multirow{2}{*}{\multicolumn{6}{|c|}{ Habits of mother and dampness of house ... }} & \multicolumn{2}{|c|}{ Rochdale Blackbı } \\
\hline & & & & & ... & $\ldots \cdot 62$ & - - \\
\hline ", & ", & ", & lighting & $\ldots$ & $\ldots$ & $\ldots \quad 54$ & - \\
\hline ", & ", & ", & overcrowding & & $\ldots$ & $\ldots .63$ & - \\
\hline ", & ", & $"$ & possibility of ventil & lation & $\ldots$ & $\ldots \cdot 65$ & - \\
\hline ", & ", & ", & type of house & $\cdots$ & $\cdots$ & ... $\cdot 55$ & - \\
\hline \multirow{2}{*}{\multicolumn{4}{|c|}{ Cleanliness" of home and overcrowding }} & $\cdots$ & $\cdots$ & ... $\cdot 49$ & 一 \\
\hline & & & & $\ldots$ & $\ldots$ & ... $\cdot 57$ & -42 \\
\hline$"$, & , & ", & number of rooms & & $\cdots$ & ... $\cdot 37$ & $\cdot 24$ \\
\hline ", & , & ," & rent $\quad \ldots$ & $\cdots$ & $\cdots$ & $\cdots$ & $\cdot 29$ \\
\hline " & $"$ & " & type of house & $\cdots$ & ํ. & $\ldots \cdot 4^{2}$ & \\
\hline \multicolumn{3}{|c|}{ General mean, $\bullet 483$} & $\left\{\begin{array}{l}\text { Mean of "habits" } \\
\text { Mean of " cleanline }\end{array}\right.$ & $\begin{array}{l}\operatorname{cor} \\
\text { ess }\end{array}$ & $\begin{array}{l}\text { latior } \\
\text { orrela }\end{array}$ & ons & $\cdot 380$ \\
\hline
\end{tabular}

We have found that on the whole the direct parental factors appear to be more closely correlated with physical environmental factors than with the indirect parental factors, although certain of the latter correlations are high, e.g. between habits of mother and father's occupation, 55 (Rochdale), between means of family and habits of mother 67 (Rochdale), between habits of father and occupation of father 4 I (Bradford). It cannot therefore be asserted that even the physical environmental factors are free from the nature influence. The parents of the worse health and habits are found in the lower type of physical environment, and thus even the slight association of worse physical environment with lesser welfare of infant and childlife may in part or wholly be due to the direct parental factors; in part if we believe health but not habits to be hereditary, wholly, if we consider orderliness and briskness of mind, nay, even the power to receive and carry on a tradition to be essential parts of our mental inheritance.

In any case we are in a position to sum up the problem of the relative intensity of Nature and Nurture as illustrated by the data for mortality of infants and health of surviving children from the towns of Rochdale, Bradford and Blackburn. If we pool all environmental factors, we shall not reach an average correlation higher than 'Io with the welfare of offspring, while the interenvironmental correlations will be at least of the average order 40 , and accordingly by Table IV an infinity of such factors could only provide a multiple correlation of $\cdot 158$, for nurture as against the nature value for two 
parents of $\cdot 707$. Thus the nature value is at least 4.5 times the nurture value. But this is a minimum value of the relative intensity. If we pick out the physical environmental factors and the indirect parental factors the mean correlation corrected for either health or habits only is $\cdot 055$, and the mean interenvironmental correlation of the order 60 , which provide by Table IV in the case of an infinity of environmental factors for a multiple correlation of $07 \mathrm{I}$. This is just one-tenth of the nature factor 707 , as represented by two parents. But the value .055 is probably too large; it is not only higher than the value found for material from other districts (see Table II), but we have seen that the direct parental factors are very sensibly correlated with the physical environment. The mean physical environmental correlation is hardly likely to exceed $\cdot 03$ or $\cdot 04$, which with an interenvironmental correlation of 60 leads to a multiple correlation for an infinity of factors of only $\cdot 04$, or $\cdot 05$-not more than $\frac{1}{14}$ th to $\frac{1}{18}$ th of the value of the intensity of nature as represented by the inheritance from two parents. In other words our present results fully confirm the earlier statement that the relative intensity of nature was five to ten times that of nurture. We have chosen the cases of infant mortality and delicacy of childhood for consideration as these are usually considered to be peculiarly the outcome of the physical environment. As a matter of fact the most influential post-natal factors are parental health and parental habits, matters least susceptible of modification by act of parliament or municipal regulation, unless we forbid parentage to the unhealthy or place in the stocks parents who refuse to open their windows, or who spend money on other matters than food. I feel confident that within the limits to which we have applied our statements-to the range of infantile and child nurture-and to those variations of environment which fall within the field of experience or of practical politics our assertion that nature is five to ten times as influential as nurture is free from any exaggeration and forms a solid ground upon which to base the direction of reforms which shall accelerate racial progress. It is five to ten times as profitable for a child to be born of parents of sound physique and of brisk, orderly mentality as for a child to be born and nurtured in a good physical environment. To state this is not to discredit all improvement of environment; such improvement adds greatly to the amenities and to the possibilities of human life, but it is to parentage itself that the patriot who would work for racial progress must turn in the first place, if he would achieve a greater success than the environmentalists with a 
century of social reform have hitherto been able to claim. This is the sole ground on which the eugenist is distinguished from the old social reformer, and those who fail to realise this emphasis of nature over nurture are entirely missing not only Galton's methods of investigation, but the essential feature of what he understood by eugenics.

Yet what do we find is the present state of affairs with regard to any really scientific study of sociological or racial problems? Why that such study is met by wholly uncritical or often unthinking attacks-attacks which show that their writers neither appreciate the facts already known to us, nor grasp in the slightest degree the methods by which alone these facts can be analysed. They honour Francis Galton without studying what he devoted his life to demonstrating; they establish an anniversary festival to his memory, and at the same time deny the actual validity of the calculus which he first introduced to solve these very problems of nature and nurture. They talk idly of using "words in scientific literature without endeavouring to attach a definite meaning to them" although the man they proclaim as a leader had shown how to obtain a definite quantitative measure of these very words. They talk vaguely about "large fallow areas of the brain" still uncultivated and state that "instead of attaching too much importance to nurture we have not yet begun to attach enough" ; they trust to verbal discussion where Francis Galton would have told them to measure and learn the facts before they spoke. It was Galton's fundamental principle that before we know the meaning of anything we must measure it, and that ultimately everything would be found capable of measurement, if we use its own appropriate footrule. I have even a letter from him in which he discusses how we could obtain a definite numerical measure of the influence of Mrs Grundy upon social reform. The one thing that wearied Galton's almost inexhaustibly enthusiastic nature was a torrent of words without any admixture of measured facts. $\mathrm{He}$ invariably judged the worth of a publication by the extent of its appeal to statistical data in the form either of observation or experiment. Yet all this appears wholly forgotten by those who trumpet most loudly his name. Again I ask: What results do they suppose Galton reached and by what methods do they suppose he reached them? The reality is summed up in the words of Galton himself, which form the motto of our Biometric Laboratory: 
"Until the phenomena of any branch of knowledge have been submitted to measurement and number, it cannot assume the status and dignity of a science."

Those who do not realise that this was the essence of Galton's teaching, those who believe that they can solve the extremely difficult problems of race-progress and of eugenics by mere verbal discussion will only succeed in bringing his name and his work into discredit. 
mbridge University Press, Fetter Lane, London, E.C., and their Agents, e now the sole agents for the sale of the following publications of the ulton and Biometric Laboratories, University of London:

\section{BIOMETRIC LABORATORY PUBLICATIONS Drapers' Company Research Memoirs.}

\section{Biometric Series.}

(thematical Contributions to the [Cheory of Evolution.-XIII. On the Theory of Contingency and its Relation to Associaion and Normal Correlation. By KARL Pearsos, F.R.S. Price 4s. net.

athematical Contributions to the ITheory of Evolution.-XIV. On the Theory f Skew Correlation and Non-linear Regression. By Karl Pearson, F.R.S. Price $5 s$. net.

athematical Contributions to the Theory of Evolution.-XV. On the Mathematical Theory of Random Migration. By Karl Pearson, F.R.S., with the assistance of John Bla keMan, M.Sc. Price 5s, net. athematical Contributions to the Theory of Evolution.-XVI. On Further Methods of Measuring Correlation. By Karl Pearson, F.R.S. Price 4s, net.
V. Mathematical Contributions to the Theory of Evolution.-XVII. On Homotyposis in the Animal Kingdom. A Cooperative Study.

[Shortly.

VI. Albinism in Man. By KarL Pearsox, E. Netrleship, and C. H. Usher. Text, Part I, and Atlas, Part I. Price 35s. net.

VII. Mathematical Contributions to the Theory of Evolution.-XVIII. On a Novel Method of Regarding the Association of two Variates classed solely in Alternative Categories. By KarL Pearson, F.R.S. Price 4s. net.

VIII. Albinism in Man. By KarL Pearson, E. Nettleship, and C. H. Usher. Text, Part II, and Atlas, Part II. Price 30 s. net.

IX. Albinism in Man. By KarL Pedrson, E. Nettleship, and C. H. Usher. Text, Part IV, and Atlas, Part IV. Price 21 s. net.

\section{Studies in National Deterioration.}

1. the Relation of Fertility in Man ito Social Status, and on the changes in this Relation that have taken place in the last 50 years. By David Heron, M.A., D.Sc. Price 3s. net. Sold only with complete sets. First Study of the Statistics of Pulmonary Tuberculosis (Inheritance). By Karl Pearson, F.R.S. Price 3s. net.

Second Study of the Statistics of Pulmonary Tuberculosis. Marital Infection. By ERnest G. Pope, revised by KarL Pearson, F.R.S. With an Appendix on Assortative Mating by ETheL M. ELderToN. Price 3s. net.

he Health of the School-Child in relation to its Mental Characters. By KarL Pearson, F.R.S. Shortly. the Inheritance of the Diathesis of Phthisis and Insanity. A Statistical Study based upon the Family History of 1,500 Criminals. By Charles Goring, II.D., B.Sc. Price 3s. net.

\section{Technical Series.}

n a Theory of the Stresses in Crane and Coupling Hooks with Experimental Comparison with Existing Theory. By E. S. ANDREWs, 1.Sc. Eng., assisted by Kart Pearson, F.R.S. Issued. Price 3s.net. in some Disregarded Points in the Stability of Masonry Dams. By L. W. Atcherlex, assisted by Karl Pearson, F.R.S. Issued. Price 3s. 6d. net.

in the Graphics of Metal Arches with special reference to the Relative Strength of Two-pivoted, Three-pivoted and Built-in-Metal Arches. By L. W. Atcherley and Karl Pearson, F.R.S. Issued. Price 5s. net.
VI. A Third Study of the Statistics of Pulmonary Tuberculosis. The Mortality of the Tuberculous and Sanatorium Treatment. By W. P. Elderton, F.I.A., and S. J. Perry, A.I.A. Price 3s. net.

VII. On the Intensity of Natural Selection in Man. (On the Relation of Darwinism to the Infantile Death-rate.) By E. C. Svow, D.Sc. Price 3s. net.

VIII. A Fourth Study of the Statistics of Pulmonary Tuberculosis: the Mortality of the Tuberculous: Sanatorium and Tuberculin Treatment. By W. Palis Elderton, F.I.A., and Sidney J. Perry, A.I.A. Price 3s. net.

IX. A Statistical Study of Oral Temperatures in School Children with special reference to Parental, Environmental and Class Differences. By M. H. Williass, M. B., Julia BeLL, M.A., and KARL Pearson, F.R.S. Price 6s. net.

IV. On Torsional Vibrations in Axles and Shafting. By Karl Pearson, F.R.S. Issued. Price 6s. net.

V. An Experimental Study of the Stresses in Masonry Dams. By KarL Pearson, F.R.S., and A. F. Campbel Pollard, assisted by C. W. Wheen, B.Sc. Eng., and L. F. RicHARDSON, B.A. Issued. Price 7s. net.

VI. On a Practical Theory of Elliptic and Pseudo-elliptic Arches, with special reference to the ideal Masonry Arch. By KARr Pearson, F.R.S., W. D. Reynolds, B.Sc. Eng., and W. F. Stanton, B.Se. Eng Issued. Price 4s. net. 


\section{Drapers' Company Research Memoirs-(cont.).}

\section{Questions of the Day and of the Froy.}

I. The Influence of Parental Alcoholism on the Physique and Ability of the Otfspring. A Reply to the Cambridge Economists. By Karl Pealuson, F.R.S. Price 18. net.

II. Mental Defect, Mal-Nutrition, and the Teacher's Appreciation of Intclligence. A Reply to Criticisms of the Menoir on - The Intiuence of Defective Pliysique and Unfavourable Home Environment on the Intelligenec of School Childreu.' By DAvid Heros, D.Sc. Price 1s. net.

III. An Attempt to correct some of the Misstatements made by Sir VICTOR HorsLEY, F.R.S., F.R.C.S., and MARY D. StURGE, M.D., in their Criticisms of the Memoir : 'A First Study of the Influence of Parcntal Alcoholism,' Sc. By Kard Pearson, F.R.S. Price 18. net.
IV. The Fight against Tuberculosis the Death-rate from Phthisis. By

PEARSON, F.R.S. P'rice ls, wet.

V. Social Problems: Their Treatm Past, Present and Future. By Pearson, F.R.S. Price 18. net.

VI. Eugenics and Public Health. Le to the York Congress of the Royal Sar Institutc. By KarL PEArsos, F.lR.S. 18. net.

VII. Mendelismand the Problem of Me Defect. I. A Criticism of Recent Ame Work. By David HeroN, D.Sc. (D Number.) Price 2s. net.

VIII. Mendelism and the Problem of Me Defect. II. The Continuity of $M$ Defect. By Kard Pearson, F.R.S. Gustav A.Jaeverhola, Ph.D. Price I

IX. Mendelism and the Problem of Mental Defect. III. On the Graduated Clarac Mental Defect, and ou the need for standardizing Judgments as to the Grade of Social Incficio which shall involve Segregation. By Karl Pearsox, F.R.S. (Double Number.) Price 28.

\section{Eugenics Laboratory Publications}

\section{MEMOIR SERIES.}

I. The Inheritance of Ability. By EDGAR SchUSTER, D.Sc., Formerly Galton Research Fellow, and Ethel M. Édentox, Galton Scholar. Price 48. net.

II. A First Study of the Statistics of Insanity and the Inheritance of the Insanc Diathesis. By David Heros, D.Sc., Formerly Galton Research Fcllow. Price 3s. net.

III. The Promise of Youth and the Performance of Manhood. By EDGAR Schuster, D.Sc., Formerly Galton Research Fcllow. Price 28. 6d. net.

IV. On the Measure of the Resemblance of First Cuusins. By Exhel M. Eldertos, Galton Reseurch Fellow, assisted by KARL Pearson, F.R.S. Price 3s. 6d. net.

V. A First Study of the Inheritance of Vision and of the Relative Influence of Heredity and Environment on Sight. By AmY Barrisgton and Karl Pearsos, F.R.S. Price 4s. net.

VI. Treasury of Human Inheritance (Pedigrees of physical, psychical, and pathological Characters in Man). Parts I and II (double part). (Diabetes insipidus, SplitFoot, Polydactylism, Brachydactylism, Tuberculosis, Deaf-Mutism, and Legal Ability.) Price 14s. net.

VII. The Infiuence of Parental Occupation and Home Conditions on the Physique of the Offspring. By Eithel. M. Eldertos; Galton Research Fellow. Shortly.

VIII. The Influence of Unfavourable Home Environment and Defective Physique on the Intelligence of School Children. By David Herox, M.A., D.Sc., Formerly Galton Research Fellow. Price 4s. net. Sold only with complete sets.

IX. The Treasury of Human Inheritance (Pedigrees of physical, psychical, and pathological Characters in Man). Part III. (Angioneurotic Oedema, Hermaphı。oditism, Deaf-Mutism, Insanity, Commcrcial Ability.) Price 6s. net.
X. The Influence of Parental Alco on the Physique and Intelligence Offspring. By ETHEL M. ELDER sisted by Karl Pearsox. Second Price 4s. net.

XI. The Treasury of Human Inher (Pedigrees of physical, psyclical, an logical Characters in Man). P (Cleft Palate, Hare-Lip, Deaf-MLuti Congenital Cataract.) Price 10s.?

XII. The Treasury of Human Inher (Pedigrees of physical, psychical; an logical Characters in Man). Part VI. (Haemophilia.) Price 15s.n。

XIII. A Second Study of the Influe Parental Alcoholism on the Physis Intelligence of the Offspring. $B$ Pearsox, F.R.S., and Ethel M. Fl Price 4s. net.

XIV. A Preliminary Study of Ex Alcoholism in Adults. Ву Азг B. TON and KARL PEARSON, F.R.S., by David Herox, D.Sc. Price $4 s$.

XV. The Treasury of Human Inheri Dwarfism, with 49 Plates of Illus and 8 Plates of Pedigrecs. Price 1

XVI. The Treasury of Human Inheri Prefatory matter and indices to With Frontispiece Portraits of Sir Galton and Ancestry. Price 38. nei

XVII. A Second Study of Extreme. holism in Adults. With special $\mathrm{rc}$ to the Home-Office Incbriate Refor data. By David Herox, D.Sc. Price

XVIII. On the Correlation of Fertilit Social Value. A Cooperative Price 6s. net.

XIX-XX. Report on the English Birt Part I. Esigland, North of the H By Éthel Mi. Eldertox; Galton R Fcllow. Price 9s. net.

Vol. I of The Treasury of Human Inheritance (VI+IX+XI+XII XV+XVI of the above memoirs) may now be obtained bound in buckram, price 528. $6 d$. net. Buckram cases for 


\section{Eugenics Laboratory Publications-(cont.).}

binding can be purchased at 2s. $9 d$. with impress of the bust of Sir Francis Galton. A photograph $\left(11^{\prime \prime} \times 13^{\prime \prime}\right)$ of Sir Francis Galton by the late Mr Dew Smith can be obtained by sending a postal order for 10s. $6 d$. to the Secretary to the Laboratory, University College, London, W.C.

\section{TURE SERIES. Price 1s, net each (Nos. III and X excepted).}

The Scope and Importance to the State of the Science of National Eugenics. By Karl Pearson, F.R.S. Third Edition. The Groundwork of Eugenics. By KARL Pearsor, F.R.S. Second Edition.

The Relative Strength of Nurture and Nature. Part I. By Ethel M. Elderton. Part II. By Karl Pearson. (New and much enlarged Edition. First Edition out of print.) Price $2 s$. net.

On the Marriage of First Cousins. By Ethel M. EldertoN.

The Problem of Practical Eugenics. By Karl Pearsov, F.R.S. Second Edition.
VI. Nature and Nurture, the Problem of the Future. By Karl Pearson, F.R.S. Second Edition.

VII. The Academic Aspect of the Science of National Eugenics. By Karl Pearson, F.R.S.

VIII. Tuberculosis, Heredity and Environment. By Karl Pearsoy, F.R.S.

IX. Darwinism, Medical Progress and Eugenics. The Cavendish Lecture, 1912. By Karl Pearson, F.R.S.

X. The Handicapping of the First-born. By Karl Pearson, F.R.S. Price 2s. net.

\section{BIOMETRIKA}

\section{A JOURNAL FOR THE STATISTICAL STUDY OF BIOLOGICAL PROBLEMS}

Founded by W. F. R. Weldon, Francis Galton and Karl Pearson (Editor).

\section{CON'TENTS. Volume X. Part IV}

I. Association of Finger-Prints. By H. WAITE, M.A., B.Sc. (With Plate $\mathrm{XX}$ and Thirty Diagrams in the text).

II. On the Problem of Sexing Osteometric Material. By KarL Pearson, F.R.S. (With One Diagram in the text).

III. Further Evidence of Natural Selection in Man. By Ethel M. Eldertor and KarL PEARSON, F.R.S.

IV. Frequency Distribution of the Values of the Correlation Coefficient in samples from an indefinitely Large Population. By R. A. Fisher.

V. On the Distribution of the Standard Deviations of Small Samples: Appendix I to Papers by "Student" and R. A. Fisher. (Editorial.)

VI. Tuberculosis and Segregation. By Alice LeE, D.Sc.

VII. The Influence of Isolation on the Diphtheria Attack- and Death-rates. By Ethel M. Elderton and Karl Pearson, F.R.S. (With Two Diagrams in the text.)

Miscellanea: (i) On the Probable Error of a Coefficient of Mean Square Contingency. By Karl Pearson. (ii) Measurements of Medieval English Femora. A rejoinder to Dr F. G. Parsons. By Karl Pearson.

The subscription price, payable in advance, is 308. net per volume (post free); single numbers 10s. net. Volumes I-X $(1902-15)$ complete, 30s. net per volume. Bound in Buckram $34 / 6$ net per volume. Index to Volumes I to V, 2s. net. Sabscriptions may be sent to C. F. Clay, Cambridge University Press, Fetter Lane, London, E.C., either direct or through any bookseller, and communications respecting advertisements should also be addressed to C. F. Clay.

Till further notice, new subscribers to Biometrika may obtain Vols. I-X together for $£ 11$ net-or lbound in Buckram for $£ 13$ net.

The Cambridge University Press has appointed the University of Chicago Press Agents for the sale cof Biometrika in the United States of America, and has authorised them to charge the following prices:$\$ 7.50$ net per volume; single parts $\$ 2.50$ net each.

The following work prepared in the Biometric Laboratory can be obtained as a Government Report from Messrs Wyman and Sons, Ltd.

The English Convict, A Statistical Study. By Charles Goring, M.D.

Text. Price 9s. Tables of Measurements (printed by Convict-Labour). Price 5s. 


\title{
The Life, Letters, and Labours o Francis Galton
}

\section{Vol. I. Birth 1822 to Marriage 1853}

\section{WITH 5 PEDIGREE PLATES AND 72 PHOTOGRAPHIC PLATES, FRONTISPIECE AND 2 TEXT-FIGURES}

\author{
BY KARL PEARSON, F.R.S. \\ GALTON PROFESSOR, UNIVERSITY OF LONDON
}

"It is not too much to say of this book that it will never cease to be memorable. Never will man hold in his hands a biography more careful, more complete."-The Times

"A monumental tribute to one of the most suggestive and inspiring men of modern times."-Westminster Gazette

"It was certainly fitting that the life of the great exponent of heredity should be written by his great disciple, and it is gratifying indeed to find that he has made of it, what may without exaggeration be termed a great book."-Daily Telegraph

\section{Recently issued. Price 9s. net.}

\section{Tables for Statisticians \& Biometricians}

\author{
Editen by KARL PEARSON, F.R.S. \\ GALTON PROFESSOR, UNIVERSITY OF LONDON
}

ISSUED WITH ASSISTANCE FROM THE GRANT MAIE BY THE WORSHIPFUL COMPANY OF DRAPERS TO THE BIOMETRIC LABORATORY.

"To the workers in the difficult field of higher statistics such aids are invaluable. Their calculation and publication was therefore as inevitable as the steady progress of a method which brings within grip of mathematical analysis the highly variable data of biological observation. The immediate cause for congratulation is, therefore, not that the tables have been done but: that they have been done so well...... The volume is indispensable to all who are engaged in serious statistical work." - Science

"The whole work is an eloquent testimony to the self-effacing labour of a body of men and women who desire to save their fellow scientists from a great deal of irksome arithmetic; and the total time that will be saved in the future by the publication of this work is, of course, incalculable....... To the statistician these tables will be indispensable." -Journal of Education

"The issue of these tables is a natural outcome of Professor Karl Pearson's work, and apart from their value for those for whose use they have been prepared, their assemblage in one volume marks an interesting stage in the progress of scientific method, as indicating the number and importance of the calculations which they are designed to facilitate."-Post Magazine

\section{CAMBRIDGE UNIVERSITY PRESS \\ C. F. CLAY, MANAGER}

LONDON : FETTER LANE, E.C. EDINBURGH: 100, PRINCES STREET

H. K. LEWIS AND CO. LTD., 136, GOWEB STBEET, LONDON, W.C.

WILLIAM TESLEY AND SON, 28, ESSEX STREET, LONDON, W.C.

CHICAGO: UNIVERSITY OF CHICAGO PRESS
BOMBAY, CALCCTTA AND MADRAS : MACMILLAX AND CO., LIMITED TORONTO: J. M. DENT AND SONS, LIMITED TOKYO : THE MARUZEN-KABUSHIKI-KAISHA 
THE LIBRARY

UNIVERSITY OF CALIFORNIA

Santa Barbara

THIS BOOK IS DUE ON THE LAST DATE STAMPED BELOW.

MOTIS MAR 101990

RETD FEB 261000

CHECKEO IN FEB 26 ' 90
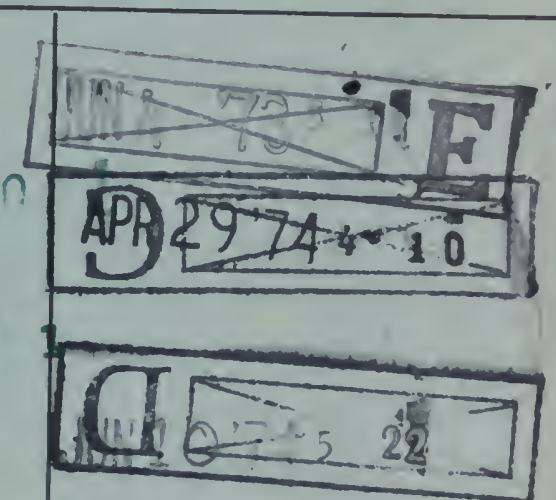

OCT i $\cap 2 \pi \cap 5$ 
$-4$ 